\title{
3-D slope stability analysis: A probability approach applied to the nice slope (SE France)
}

\author{
D. Leynaud ${ }^{\mathrm{a},{ }^{*}}$ and N. Sultan ${ }^{\mathrm{a}}$
}

a Ifremer, LES-GM, BP 70, Pointe du Diable, 29280 Plouzané, France

*: Corresponding author : D. Leynaud, Tel.: +33 540008835, email address : $\underline{\text { d.leynaud@epoc.u-bordeaux1.fr, }}$ d.leynaud@orange.fr

\begin{abstract}
:
Recent geophysical and geotechnical data acquired on the Nice shelf to the east of the 1979 landslide source area, suggest slow deformations processes which could lead to future catastrophic slope failure. According to these preliminary interpretations, it is of major interest to perform a slope stability evaluation to define the hazard and quantify the danger related to a probable instability on this slope. A probabilistic approach is proposed here using a modified version of the SAMU_3D model, a 3-D slope stability software recently developed by Sultan and others to account for complex geometry. The 3-D analysis is based on the upper bound theorem of plasticity developed by Chen and others. One of the main features of the original model is to allow complex critical failure surfaces, suitable for complex bathymetry (i.e. canyons). A probabilistic approach was added to the former deterministic model to consider the effect of sediment parameter variability and uncertainty (undrained shear strength and unit weight) on the likelihood of failure. Such an approach allows an estimation of the reliability of the results. Monte Carlo simulation was used to represent the variability of the factor of safety given a specific number of trials. Identification of the critical failure surface previously based on a deterministic analysis is thus performed in terms of probability of failure (or probability of a factor of safety lower than a reference value). According to the undrained shear strength distribution profiles with depth, obtained using different models (down to 30 and $60 \mathrm{~m}$ depth) at several sites and to the parameter uncertainty, high probability of failure (around 50\%) is found for the Nice slope indicating that the sediment in this area is highly metastable.
\end{abstract}

Keywords: probabilistic analysis; slope stability; Monte Carlo simulation; shear zone 


\section{Introduction}

Submarine slope failures are one of the main processes for long-distance sediment transport and for shaping seafloor morphology. In addition, they represent an important hazard to the coastal community as well as the off-shore exploitation of marine resources. Slope stability assessment methods are of major interest to evaluate the likelihood of failure and the danger associated with such events. In many cases, the conventional deterministic slope stability analysis corresponds to a simplification of the problem, providing results based on averaged sediment parameters which tend to eliminate the effect of parameter uncertainty on the estimated performance of the slope. Probabilistic methods allow refining conventional evaluations by integrating specific data variability related to the site into the final result. On the other hand, a 3-D slope stability evaluation allows us to propose more realistic failure surfaces represented by complex shapes associated with complex bathymetry and obviously a more realistic safety factor compared to the 2-D approach. The SAMU_3D software (Sultan et al., 2007 N. Sultan, M. Gaudin, S. Berné, M. Canals, R. Urgeles and S. Lafuerza, Analysis of slope failures in submarine canyon heads: an example from the Gulf of Lions, Journal of Geophysical Research 112 (2007), p. F01009 10.1029/2005JF000408. Full Text via CrossRef | View Record in Scopus | Cited By in Scopus (4)Sultan et al., 2007) was developed to face this problem using a broad range of complex shapes to test the 
critical failure process. This paper addresses the integration of a probabilistic method in the recent 3-D slope stability evaluation software (SAMU_3D) by using the Monte Carlo simulation. Numerous examples showed the interest of the probabilistic method for geohazard problems (Nadim, 2002; Nadim and Lacasse, 2003; Lacasse and Nadim, 2007). The latter be applied to the present-day Nice shelf and slope (Figure 1), south coast of France, where a significant slide took place on October 16, 1979.

The 1979 lanslide (Figure 2) occured at the place of the fill used during the construction of the new Nice harbour with a removed sediment mass estimated between 2 to 3 million $\mathrm{m}^{3}$ of fill and about 7 millions $\mathrm{m}^{3}$ of underlying sediments, mainly clayey silt and silty sand, which composes the deltaic deposits (Seed et al., 1988). Gennesseaux et al. (1980) showed that a

flow of several hundred million $\mathrm{m}^{3}$ of sediment was likely at the origin of the cable breaks at distances of about 90 and $120 \mathrm{~km}$ off-shore from Nice, suggesting a significant erosion process downslope following the initial event. According to Mulder et al. (1997), the initial slide then turned into a debris flow and turbidity current with progressive erosion and water incorporation. Despite a series of observation reported from different witnesses, the triggering mechanics and the precondition to failure was not well understood.

More recently, Dan et al. (2007) proposed a new slope stability assessment of the Nice slope based on sediment cores and piezocone CPTU data; the latter highlight the presence of a sensitive clay bed between $30 \mathrm{mbsl}$ and $45 \mathrm{mbsl}$. Numerical simulations show that under high deviatoric load, creeping of the sensitive clay layer could lead to a shear resistance loss and thus be at the origin of the 1979 slide. A decrease of the effective stress induced by seepage of freshwater due to the exceptionally heavy rainfall is likely the triggering mechanisms which led to the Nice slope failure. The "sensitive layer" hypothesis is supported by the good correlation between the maximum thickness of the sliding mass and the depth of the sensitive clay layer. Furthermore, the progressive failure scenario according to the creeping process 
83

agrees well with the observations mentioned in the official report (cracks, settlements, failures, collapses) during land filling operations.

Beyond the 1979 accident the aim of this paper is to provide a new approach to highlight the significant hazard related to present-day slope at the Nice shelf area. A present-day slope stability evaluation in the vicinity of the 1979 landslide area will be performed thanks to the piezocone CPTU data recovered recently during the 2007 PRISME cruise (Sultan et al., 2008).

\section{Deterministic 3-D slope stability analysis} 93

For complex and heterogeneous slopes, 1-D or 2-D slope stability analysis is untimely and is prone to lead to oversimplification with inaccurate results, especially when sediment layer thicknesses are variable along the slope. In this case, a 3-D analysis is required for an accurate evaluation of the slope stability. The SAMU_3D software (Sultan et al., 2007) proposes a 3-D stability analysis method based on the upper bound theorem of plasticity (Chen et al., 2001a, 2001b); the latter method avoids simplifications related to the use of the limit equilibrium methods concerning static and kinematic admissibility (Yu et al., 1998). The second interest of the SAMU_3D software concerns the complex geometry proposed to test the failure surfaces and simulate the critical one. The equation defining the shape of an arbitrary failure surface depends on eight parameters which allow to test a broad range of geometries prone to sliding and thus to get the corresponding range of factor of safety. The kinematically admissible velocity field implies that plastic velocity be inclined at an angle $\varphi^{\prime}$ (internal friction angle) to the failure plane. 
109 Probabilistic approach

111 The impact of soil parameters variability (or model uncertainty) on a slope stability

112 assessment can be evaluated through the use of probability methods. Many published studies

113 tackle the soil parameters uncertainty through 2D slope stability evaluations even though the

114 use of the 2D-domain generates an error inherent to the problem simplification. We have here

115 the opportunity to combine a 3D model to a probability approach in order to provide a more

116 realistic evaluation of the slope stability conditions.

117 The modified SAMU_3D software proposes a search algorithm for locating the critical slip

118 surface with the highest probability of failure instead of the lower safety factor as this is

119 commonly done with the deterministic approach. The probability of failure is calculated using

120 a Monte Carlo simulation which provides a set of deterministic safety factors corresponding

121 to a series of trials. Monte Carlo simulation is a class of computational algorithms for

122 simulating the behaviour of physical systems using random (or pseudo-random) numbers. The

123 simulation is based on the repetition of algorithms with a large number of calculations

124 involving variables defined with probability distributions. This results in a series of number

125 with a specific distribution (mean and standard deviation) allows to estimate the probability of

126 getting the unknown final parameter (i.e. factor of safety) in a certain range of values.

127

128

129

130

131 The development of a Monte Carlo scheme is quite simple. Some input parameters defining

132 the model are represented using a probability distribution which allows computing a set of 
133 resulting safety factors according to the parameters uncertainty. Many random variables

134 distribution (for geotechnical engineering material properties) appear to be well represented or 135 approximated by a normal Probability Density Function (PDF) but others distribution types 136 are available (lognormal, uniform, triangular, etc...). The normal distribution is used in this

137 paper to represent both the distribution of undrained shear strength and unit weight. Then, the 138 probability to get a value $x$ ( $x$ is the variable of interest) lying between $\pm 1 \sigma$ ( $\sigma$ is the 139 standard deviation) is $68 \%$. In other words, this means that if a soil has a mean cohesion of $14034.5 \mathrm{kPa}$ with a standard deviation of $8.14,68 \%$ of a series of samples should have their value 141 between $26.36 \mathrm{kPa}(34.5-8.14)$ and $42.64 \mathrm{kPa}(34.5+8.14)$.

142 In equation form, this gives for the normal distribution,

$144 f(x)=\frac{e^{-(x-u)^{2} / 2 \sigma^{2}}}{\sigma \sqrt{2 \pi}}$

146 where $\mathrm{u}$ is the mean value of $x$.

$148 \quad$ Figure 3 shows two typical normal distributions with different means and standard

149 deviations. One with low mean and low standard deviation (PDF 1) and another one with high 150 mean and high standard deviation (PDF 2). Though the PDF 1 mean value is closer from the 151 unity (and thus from the failure domain), the higher probability of failure corresponds to PDF 1522 according to the respective areas for factors of safety below 1.0 (Figure 3; left diagram).

153 These functions are defined without any limit but truncations can be applied if minimum and 154 maximum values are specified.

156 The procedure for modelling a variable probability distribution from its mean and standard deviation is decomposed in four steps: 
1) Define the probability density function representing as well as possible the natural data set for each parameter assumed to show variability.

160 2) Calculate the Cumulative Distribution Function which provides the probability to get

161 values from measurements in a specific range.

162 3) Invert the previous function in order to get a percent point function or a sampling function;

163 the latter allows to get some values around a specific parameter according to their previously

164 defined distribution. In the sampling function, the $\mathrm{x}$-axis represents the range of expected

165 random numbers; for each random number generated, the function generates a parameter

166 whose occurrence frequency corresponds to the previously defined distribution.

167 4) Generate a series of aleatory (or pseudo-aleatory) numbers which will provide, in

168 combination with the sampling function, a series of values corresponding to the expected

169 frequency distribution.

170

171 Then, calculations using the former deterministic model are made with each data set of

172 generated values to get a distribution of results as this could be expected in reality. From the

173 resulting distribution of factors of safety, it is then easy to estimate the probability of failure

174 (or the probability to have a factor of safety lower than a reference value if no factor of safety

175 below 1.0 is found). In this paper, the modified SAMU_3D program calculates a safety factor

176 associated to $5 \%$ probability to be lower than this reference value. The latter level (5\%) was

177 defined to ensure that the probability is representative of the standard deviation rather than the

178 average value of the normal distribution. Figure 3 (right diagram) shows an example for

179 which $5 \%$ probability are calculated for both distributions; the latter provides $5 \%$ probability

180 to have a factor of safety below 1.025 and 0.68 with PDF 1 and PDF 2 respectively. In terms

181 of probability of failure, PDF 2 corresponds to the most critical one. The program keeps in

182 memory the lowest factor of safety from different trials associated to $5 \%$ probability to find a 
183

184

value below this reference in the distribution which is equivalent to the probability of failure as search criterion. The number of trials was tested between 100 and 1000 to ensure this parameter has no significant effect on calculation results.

It is worth noting that the spatial variability of soil parameters was not considered in calculations; this means that for each trial, the parameters were considered constant over the length of each layer. This leads to provide lower safety factors and thus lower constant with $5 \%$ probability to have a factor of safety lower than the reference value. The failure probability is calculated when one factor of safety at least out of the total number of trials is found below 1.0.

\section{Validation of the 3D-deterministic model}

A validation of SAMU-3D is proposed with a simple case studied by many researchers; the critical slip surface and corresponding safety factor are searching for a 3D homogeneous slope. The dimensions of the study area are $25^{*} 40$ meters and the slope gradient is about $26^{\circ}$ (1:2). The soil parameters are those used by Xie et al. (2004) and are:

$c=9.8 \mathrm{kPa} \quad ; \phi=10^{\circ} \quad ; \gamma=17.64 \mathrm{kN} / \mathrm{m}^{3}$

The critical slip surfaces are proposed for two different shapes; a rectangular shape for direct comparison with Xie et al. (2004) results and a free shape to get the critical surface corresponding to the lowest safety factor; the latter was considered to show the interest of using a complex geometry with the energy approach (SAMU_3D).

The comparison of different modelling (2D and 3D-models) for this simple case is shown in Table 1. The 3D-safety factors obtained with SAMU_3D (FOS=1.41 and FOS=1.35; Figures 4 and 5) are in good agreement with the 3D-safety factor resulting from Monte Carlo 
simulation performed by Xie et al. (2004; FOS=1.42). The complex geometry of the critical

209 failure surface proposed by SAMU_3D allows to get a factor of safety below 1.40. The others

210 2D-calculations provide lower safety factors (FOS below 1.35) as expected for the 2D-

211 models.

Validation of the 3D-probabilistic model: the James Bay embamkment

Another validation concerning the probabilistic approach results is proposed with the James

Bay embankment. This case was well studied in terms of probability for 2-D models by

Christian et al. (1994) and El-Ramly et al. (2002). The embankment, composed of sand, is 12 $\mathrm{m}$ height with a $56 \mathrm{~m}$ wide berm at mid-heigth between both slopes (Figure 6). Below the sand, there is a succession of soils; clay crust ( $4 \mathrm{~m}$ on average), marine clay ( $8 \mathrm{~m}$ on average), lacustrine clay ( $6.5 \mathrm{~m}$ on average) and the underlying till layer with relative high strength. In terms of uncertainty, the main concern is the large scatter in the strength measurements for Marine and Lacustrine clays leading to high standard deviations for the latter. Ladd (1983, 1991) and Christian et al. (1994) quantified the data dispersion for eight parameters whose variability was considered in the stability analysis (Table 2).

The variables are modelled using a normal density distribution function and are truncated to +/- 3 standard deviations for the strength of the marine and lacustrine clay as for Khran \& Lam (2004 \& 2007) and for El-Ramly et al. (2002). The critical failure surface considered by

229 Christian et al. (1994) and El-Ramly et al. (2002) has a circular shape and is shown on Figure 
properties for each layer during computation (no variability of soil properties with distance in the same layer).

Using the 3D probabilistic model (SAMU_3D_PROB), the critical slip surfaces are found for a safety factor around 1.80 (Figure 8). This is well above the previous 2-D-results (FOS=1.46; Christian et al., 1994; El-Ramly et al., 2002). The ratio of 3-D and 2-D safety factor is commonly around 1.1 (Christian et al., 1994) which should provide a factor of safety around 1.6 considering the 2-D lowest safety factor (FOS=1.46). In the 3-D model, the neutral line corresponds to the 2-D critical slip surface but the other adjacent lines constituting the 3D shape being shallower (from the deepest part up to the sediment surface), the resulting safety factor is obviously higher since the sliding is easier on a deeper surface in this case.

\section{The Nice airport area}

On $16^{\text {th }}$ of October 1979 , a significant slide occurred on the Nice continental slope in the vicinity of the airport (Figure 2). In this area, the slope gradient is rather high and can reach up to $40^{\circ}$ (Figure 9). This disastrous event led to the loss of human lives and substantial damages. A part of the platform enlargement, corresponding to an extension of the Nice airport fated to be a harbour, collapsed into the sea, generating a tsunami wave of 2-3 meter height (Genesseaux et al., 1980). Seed et al. (1988) highlight the very heavy rainfall (about 25 $\mathrm{cm}$ in 4 days) which preceded the slide during several days, increasing the artesian pressure in

252 the pervious layers of the delta deposits. The authors proposed an early interpretation of the 253 observed events preceding the slide, which involves a massive under-water landslide triggered 254 by a slide in the port fill, and the resulting landslide-induced tidal wave. However authors raises an important question concerning the mechanism at the origin of the slide in the port 
1979 Nice event was considered by Seed et al. (1988) highly unlikely after examination of clays and clayey silts recovered in the area. Computed factors of safety for slip surfaces extending to bottom of clayey silt layer provided a critical value around 1.35 for conditions after construction of fill and considering artesian pressure increase.

Finally, Seed et al. (1988) concluded that the most likely cause of the slide is a static liquefaction process affecting the loose silty sand triggered by a tidal drawdown; the latter phenomenon was associated to a tidal wave generated by a submarine slide in the Var canyon about $15 \mathrm{kms}$ off-shore. The authors mentioned another hypothesis they considered unlikely, involving a failure occurring initially in the port fill and resulting in a landslide which generates a tidal wave.

Numerous examples of landslides in coastal environments are suspected to be associated with a period of low tide preceding the event (Orkdals Fjord slide, Norway, Terzaghi, 1956; Trondheim Harbor slide, Norway, Andresen \& Bjerrum, 1967). It is also worth noting that similar pore pressure conditions in the soil (artesian pressure) were reported for the Nice airport area as well as for the Orkdals Fjord (Seed et al., 1988).

Based on CPTU data and numerical modelling, Dan et al. (2007) proposed a scenario involving a sensitive clay layer between 30 and 45 mbsf and a creep process to explain the slope failure. This hypothesis is supported by the good agreement between the maximum thickness of the removed sediment and the depth of the sensitive clay layer. The authors highlight the metastable situation of the Nice slope prior to the platform enlargement and confirm the on-site observations during land filling operations (cracks, settlements, failures and embankment collapses) with a long-term creeping failure scenario.

\section{Recent Observations from bathymetry, geotechnical and geophysical data}


Recent geophysical and geotechnical data acquired by Sultan et al. (submitted) bring evidences of slow post-slide deformations and confirm the need to control the present-day stability of the slope resulting from these significant processes evolving with time.

The slope gradient map (Figure 9), achieved using bathymetric data resulting from the 1979 event, display a series of quite visible escarpments around the slide scar, bordering the airport on the shelf (ESC1 to ESC5). The latter might result from the 1979 slide event or suggest a post-slide on-going slow deformation process downslope the shelf, following the 1979 slide event. The combination of both scenari is also possible with the 1979 slide event initiating the escarpments which are now in an on-going process of deformation.

According to Demers et al. (1999), a reduction in tip resistance of about 10-50\% observed using piezocone profiles could be attributed to plastic zones related to progressive failure phenomena. In other words, creep and progressive failure would be associated with a loss of strength in the clay mass. This means that piezocone tests performed in the Nice shelf area showing a reduction of the tip resistance of $10-40 \%$ on specific sites (40\% at site $12-02$;

Figure 10) could suggest a softening of the clay related to a progressive deformation in a slope of precarious stability such as the Nice slope and lead to failure conditions in a short or medium term.

Furthermore, during the PRISME cruise (2007), a series of $3.5 \mathrm{kHz}$ sediment penetration profiles were acquired on the shelf near the 1979 event slide scar; one of them is represented on Figure 11 (3.5 khz profile CH43001). The profiles displays some features (seismic discontinuities) on the border of the shelf suggesting processes such as slow displacements of the sediment mass, in agreement with the shear zone expected from CPTU data (Figure 10). According to these evidences, we propose to carry out an new evaluation of the present-day slope stability in the vicinity of the slide area using the probability approach associated to the 
305 SAMU_3D software (Sultan et al., 2007) based on new data recovered during the 2007

306 PRISME cruise (Sultan et al., 2008).

\section{Case study: The Nice airport}

According to a probable progressive deformation in the vicinity of the Nice airport slope, the

311 slope stability in this area should be performed in terms of drained conditions. In the absence

312 of data such as cohesion and internal friction angle, the undrained conditions will be

313 considered as the critical ones in the present slope stability evaluation. Drained conditions will be considered during a next stage, when soil parameters will be available.

\section{Materials}

318 CPTU data and cores recovered in the vicinity of the slide scar during the PRISME cruise

319 were used for this study (Figures 12 and 14). CPTU data enable to model the undrained shear

320 strength profile versus depth (Figure 13) while cores provide information about unit weight

321 of the sediment (Figure 15). The latter are the two main parameters associated to the

322 bathymetry for this slope stability assessment.

\section{Undrained shear strength}

326 An empirical relation relates $S_{u}$ (undrained shear strength of the sediment) to the corrected

327 cone resistance and allows the modelling of the Su distribution with depth (Robertson \&

328 Robertson, 2006); 


$$
S_{u}=\frac{\left(q_{t}-\sigma_{v o}\right)}{N_{k}}
$$

332 where $q_{t}$ is the corrected cone resistance, $\sigma_{v o}$ is the total in situ vertical stress and $N_{k}$ is an 333 empirical cone factor. According to Lunne et al. (1997) and Robertson \& Robertson (2006), 334 the $N_{k}$ parameter varies from 10 to 20 for normally consolidated marine clays. An average 335 value of $\mathrm{Su}$ will be considered using $N_{k}=15$ while the minimum value $\left(N_{k}=20\right)$ will 336 enable to evaluate the uncertainty with depth through the standard deviation. Modelling 337 results for the 9 sites are shown on Figure 13.

338 The following step is an evaluation of the representative undrained shear strength profile with 339 depth for the slope stability assessment and the corresponding averaged uncertainty with 340 depth. This is done by using the appropriate Su profile for the area considered (model 1; down to 30 meter depth) or by averaging all the Su profiles modelled from CPTU data in a single one (model 2; down to 60 meter depth): the uncertainty is quantified by using the difference

343 between the minimum ( $S_{U}$ profile from $\left.N_{k}=20\right)$ and the mean $\left(S_{U}\right.$ profile from $N_{k}=15$ )

344 profiles and is assumed to roughly correspond to three standard deviations.

\section{Unit weight}

The unit weight of the sediment which composes the shelf southward the Nice airport area is

349 estimated from cores collected on and around the shelf using both non-destructive gamma

350 density measurements with GEOTEK MSCL (Multi-Sensor Core Logger) and direct water

351 content evaluation on samples. A series of seventeen cores were recovered from the Nice

352 shelf and slope area during the Prisme cruise (Figure 14) which enable an accurate estimate 
of the average value of the sediment unit weight on the whole zone. An example of output results regarding gamma-density measurements is shown in figure 15 with values ranging mainly between 1.8 and $2.0 \mathrm{~g} / \mathrm{cm}^{3}$ for the sediment recovered inside the slide scar as well as for the sediment found on the shelf.

\section{Model 1 (failure expected down to 30 meter depth)}

The $S_{U}$ distribution with depth profile used to represent the sediment column depends on the location of the expected failure surface. For example, the $S_{U}$ profile 12-2 (from CPTU site 12-2) is assumed to represent the $S u$ distribution with depth (equation (1) and $N_{k}=15$;

Figure 13) in the western part of the shelf, down to 30 meter depth; this is done to account for local variations with depth (20-30 m) observed on $S u$ values at different sites (mainly for CPTU sites 12-2 and 12-3) and to propose a more detailed spatial evaluation of slope stability. The uncertainty for each Su model was estimated from the gap between the minimum (equation 1; $N_{k}=20$ ) and the mean (equation 2; $N_{k}=15$ ) $S u$ profiles (Figure 13).

\section{Model 2 (failure expected down to 60 meter depth)}

A second model is took into account with a single average profile for the $S u$ distribution with depth down to 60 meter; this average profile is obtained from a compilation of all the $\mathrm{Su}$ profiles available on the shelf (CPTU 11-1 to 11-6, 12-2 and 12-3), equation (2) and $N_{k}=15$

(Figure 16) and extrapolated down to 60 meter depth according to the average gradient in the first $30 \mathrm{~m}$ depth. This model emphasizes the average Su gradient in this area down to 60 meter depth, rather than local variations of $S u$ values as those observed at 20-30 meter depth, 
in order to evaluate the likelihood to get a deep failure (between 30 and 60 meter depth)

378 though any information is available for this range of depth.

\section{Standard deviation}

The standard deviation is assumed to correspond to one third the negative (or positive) uncertainty; in others words the value of negative (or positive) uncertainty is large enough to correspond to three standard deviations (Table 4). The confidence interval ( $3 \cdot \sigma$ or 3 standard deviations) is representative of $99.73 \%$ of the dataset and only $0.27 \%$ do not correspond to the probability distribution model. The uncertainty of the $S u$ models was estimated considering the gap between the minimum (equation $2 ; N_{k}=20$ ) and the mean (equation $\left.2 ; N_{k}=15\right)$ values of $S u$ profiles. For the first model (0-30 m depth) this is done using the real values for each site while for the second model (0-60 m depth) the minimum and average gradients based on the compilation of data are considered (Figure 16).

\section{Results of stability analysis}

First model (0-30m):

Figures 17 (2D-horizontal), 18 (2D-vertical) and 19 (3D) display the expected critical failure

397 surface involving the first $30 \mathrm{~m}$ of the sediment column according to the CPTU data 398 recovered on the shelf. This critical surface correspond to a probability of failure of $50 \%$ 399 (Figure 20) and is located in the area showing a strong shear strength decrease around 25 400 meter depth (15 kPa; CPTU 12-2) and a high slope gradient. The volume of sediment of the 401 most likely failed mass is around $640000 \mathrm{~m}^{3}$. It is worth noting that, in our model, the 
geometry of the layers (and the weak layer as well) is simply assumed parallel to the

403 bathymetry in the absence of further information from the other CPTU sites regarding the

404

405

406

407

408

409

410

411

412

413

414

415

416

417

418

419

420

421

422

423

424

425

426

\section{7} weak layer location (Figure 18); this is obviously at the origin of the convex shape at the bottom of the failure wake when the "weak layer" option of the SAMU-3D software provides the critical situation (higher probability of failure).

\section{Second model (0-60m)}

For the sediment mass down to 60 meter depth, the most likely failure surface is shown on

figures 21 to 23 . The safety factor corresponding to 5\% probability to get a lower value in the distribution is 1.05 (around $0.04 \%$ probability of failure from approximation; Figure 24).

This critical failure surface is found for a mean $S u$ profile (compilation of the $S u$ profiles on the shelf) extrapolated to 60 meter depth from the mean gradient between 0 and 30 meter depth and using a "free-shape" mode (different from the previous "weak layer" mode). The volume of the expected sediment mass to be removed is around $6600000 \mathrm{~m}^{3}$.

\section{Discussion} (1)

As previously mentionned, in the absence of information regarding drained conditions parameters (internal friction angle and cohesion), we propose a slope stability evaluation in terms of undrained conditions which should correspond to the critical case using the simplest approach. A more advanced evaluation for drained conditions will be performed later, with the possibility to integrate creeping and softening of the material.

The results of the 2-D (Xie et al., 2004) and 3-D (SAMU_3D; Sultan et al., 2007) stability analysis concerning the simple homogeneous slope are in good agreement (FOS=1.41 for 
both models). SAMU_3D even provides a lower safety factor (FOS=1.35) using a more complex geometry for the failure surface..

Bay model are complex; this is due to the lateral extent of the 3D-failure shape which tends to reduce the weight of the sediment column on the failure surface borders and thus increase the total safety factor. Consequently, the probability of failure decreases. Furthermore, the 1.1 ratio between the 2D and 3D analysis (Christian et al., 1994) was calculated for slope models with homogenous sediment for which the shear resistance and the unit weight did not vary with depth; the use of an heterogeneous sediment model with SAMU_3D might explain this high 2D-3D ratio (1.23).

437 Moreover, the energy approach used with SAMU-3D presents some differences compared to 438 the classical equilibrium method; one of them concerns the virtual velocity estimated for each 439 element of the model; for non-cohesive sediments, At failure, the velocity vector do an angle 440 with the failure surface which corresponds to the friction angle. This tends to draw the virtual 441 velocity vector a bit nearer of the upward direction for the elements corresponding to non442 cohesive soils and thus tends to increase the safety factor.

444 The standard deviation considered with the $S u$ profiles for the Nice slope was estimated using 445 a rough procedure but represents quite well the order of magnitude which can be expected 446 from measurements. Obviously, the resulting probability of failure strongly depends on this 447 uncertainty but remains in the range of a reasonable value for the site and the uncertainty 448 considered.

449 Down to 30 meter depth, the critical failure surface and the corresponding probability of 450 failure is obviously related to the presence and geometry of the weak layer observed on the $S u$ 451 profile (western part of the shelf). High probability of failure (50\%) is found on the western 
452 part of the shelf; this is related to the geometry of the model considered with a weak layer

453 mimicking the seafloor at a constant depth below seafloor. This model provides a specific

454 failure surface shape (weak layer mode) as shown on Figure 18. Obviously, the probability of

455 failure should be lower with a slightly inclined plane to model the weak layer (constant low

456 inclination) as the slope angle of the shear zone is preponderant in the resulting slope stability.

457 Unfortunately, there is no evidence suggesting the weak layer geometry in this area.

458

459 For the second model, the assumption made between 30 and 60 meter depth results in a

460 probability of failure less critical than using the presence of a weak layer but the mass

461 involved is well bigger (larger failure). The probability of failure $(\mathrm{FOS}<1.05)$ is still high

$462(5 \%)$ and remains in the domain of unstable conditions. The reliability index is found around

4633.6.

464 The behaviour of sensitive clay observed at 35-40 meter (Sultan et al., 2004 and Dan et al.,

465 2007) depth and the possible degradation of its resistance with time was not considered in our

466 approach.

467 Geotechnical and geophysical investigations carried out in late 2007 to the East of the 1979

468 landslide scar show the presence of several seafloor morphological steps rooted to shallow

469 sub-surface discontinuities. Moreover, in situ piezocone measurements demonstrate the

470 presence of several shear zones at the border of the shelf break at different depth below the

471 seafloor (Sultan et al., submitted). Numerical calculations carried out in the present work

472 confirm the possible start-up of a progressive failure mechanism and the very likely

473 occurrence of a future submarine landslide in the studied area.

474

475 Conclusion

476 
477 According to CPTU measurements and resulting $S u$ profiles with depth, the most critical

478 conditions for the stability of the shelf concern sediment down to 30 meter depth in the 479 western part of the shelf (CPTU 12-2).

480

481 A maximum probability of failure of $50 \%$ was estimated for the upper part of the sediment 482 column (0-30m) for the slope exposed westward (CPTU 12-2) using a weak layer surface 483 mimicking the seafloor at constant depth. A model with a planar weak layer will provide a 484 lower probability of failure but still in the range of metastable conditions.

486 Extending the $S u$ gradient observed for the sediment column in the depth range 0-30 m down 487 to 60 meter depth, the probability of failure of the corresponding sediment mass is 488 significantly reduced but still high ( $5 \%$ probability for FOS $<1.05)$ and the volume of the sediment mass likely to be removed increases.

Such results indicate that the Nice slope is highly unstable for the first 30 meter depth and that

492 further studies should be performed to sharpen this evaluation and to extend it to greater 493 depth; it is not unlikely that deeper weak layers exist, like the one observed at 30 meter depth 494 below seafloor on a couple of sites, which might increase the probability of failure of a bigger 495 sediment mass and will endanger human activities in the vicinity of the Nice airport area.

\section{Acknowledgments}

500 The development of the probability approach and the analysis of the slope stability was

501 funded by the ANR-ISIS project. The authors would like to express their gratitude towards 
502 Bruno Savoye for constructive discussions. Thanks to Virginie Mas for providing a

503 bathymetry map of the area and to Sylvia Stegmann for a preliminary review of the

504 manuscript.

505

506 References

507

508 Andresen, A., Bjerrum, L., 1967. "Slides in subaqueous slopes in loose sand and silt," in A.F.

509 Richards (ed.), Marine Geotechnique, Univ. of Illinois Press, Urbana, 1967, pp. 221-239.

510

511 Chen, Z., Wang, X., Haberfield, C., Yin, J., Wang, Y., 2001a. A three-dimensional slope

512 stability analysis method using the upper bound theorem, part I: Theory and methods, Int. J.

513 Rock Mech. Min. Sci., 38, 369-378.

514

515 Chen, Z., Wang, J., Yin, J., Wang, Y, Haberfield, C., 2001b. A three-dimensional slope

516 stability analysis method using the upper bound theorem, part II: Numerical approaches,

517 applications and extensions, Int. J. Rock Mech. Min. Sci., 38, 379-397.

518

519 Christian, J.T., Ladd, C.C., Baecher, G.B., 1994. Reliability and probability analysis, Journal 520 of geotechnical Engineering, ASCE, 120, 1071-1111.

521

522 Dan, G., Sultan, N., Savoye, B., 2007. The 1979 Nice Harbour Catastrophe revisited : Trigger 523 mechanism inferred from geotechnical measurements and numerical modelling, Marine 524 Geology, $245(1-4), 40-64$. 
526 Demers, D., Leroueil, S., d'Astous, J., 1999. Investigation of a landslide in Maskinongé,

527 Québec, Canadian Geotechnical Journal, 36: 1001-1014.

528

529 El-Ramly, H., Morgenstern, N.R., Cruden, D.M., 2002. Probabilistic slope stability analysis

530 for practice, Canadian Geotechnical Journal, 39 (3), 665-683.

531

532 Gennesseaux, M., Mauffret, A., Pautot, G., 1980. Les glissements sous-marins de la pente

533 continentale niçoise et la rupture des câbles en mer Ligure (Méditerranée occidentale). C.R.

534 Acad. Sc. Paris 290 t.

535

536 Geo-Slope International Ltd 2007. Stability modelling with Slope/W 2007. An Engineering 537 methodology, second edition, May 2007.

538

539

Krahn, J., Lam, L., 2004 \& 2007. James Bay Probabilistic Stability Analysis: A SLOPE/W

540 Case History, Prepared and printed in-house by GEO-SLOPE International Ltd, Calgary,

541 Alberta, Canada.

542

543 Lacasse, S. and Nadim, F., 2007. Probabilistic geotechnical analyses for offshore facilities.

544 Georisk, Vol. 1, No. 1, March 2007, 21_42.

545

546 Ladd, C.C., 1983. Geotechnical Exploration in Clay Deposits with Emphasis on Recent

547 Advances in Laboratory and In Situ Testing and Analysis of Data Scatter, Journal of Civil and

548 Hydraulic Engineering, Taiwan, 10(3), pp. 3-35.

549

550 Ladd, C.C., 1991. Stability Evaluation during Staged Construction, Journal of Geotechnical 
Lunne, T., Robertson, P.K., Powell, J.J.M., 1997. Cone Penetration testing in geotechnical practice, E \& FN Spon Routledge, 312 p.

Mas, V., Dennielou, B., Mulder, T., Savoye, B., Schmidt, S., Khripounoff, A., Vangriesheim,

A., 2008. "Sedimentological and hydrodynamical processes along the Var turbiditic system

Deepwater - Revisiting the Delivery Mechanisms", March 3-7, 2008, Ushuaia - Patagonie, 560 Argentine.

Mulder, T., Savoye, B., Syvitski, J.P.M., 1997. Numerical modelling of a mid-sized gravity

563 flow: the 1979 Nice turbidity current (dynamics, processes, sediment budget and seafloor 564 impact). Sedimentology 44: 305-326.

566 Nadim, F., 2002. Probabilistic methods for geohazard problems: State-of-the-Art.

567 Probabilistics in GeoTechnics: Technical and Economic Risk Estimation, Graz, Austria, 568 September 15-19.

570 Nadim, F., Lacasse, S., 2003. Review of probabilistic methods for quantification and mapping 571 of geohazards, Geohazards 2003, Edmonton, Canada, June 2003, pp 279-285.

573 Robertson, P.K., Robertson, K.L., 2006. Guide to cone penetration testing and it's application 574 to geotechnical engineering. Gregg Drilling and Testing Inc. 108 p. 
576 Seed, H. B., Seed, R. B., Schlosser, F., Blondeau, F., Juran, I., 1988. The Landslide at the port 577 of Nice on October 16, 1979, Earthquake Engineering Research Center, report No.

$578 \mathrm{UCB} / \mathrm{EERC}-88 / 10$.

579

580 Sultan, N., Gaudin, M., Berné, S., Canals, M., Urgeles, R., Lafuerza, S., 2007. Analysis of

581 slope failures in submarine canyon heads : An example from the Gulf of Lions, Journal of

582 Geophysical Research, 112, F01009, doi: 10.1029/2005JF000408.

584 Sultan, N. \& the Prisme scientific party, 2008. Prisme cruise: report and preliminary results.

Sultan, N., Savoye, B., Jouet, G., Leynaud, D., Cochonat, P., Henry, P., Stegmann, S. and

Kopf, A., submitted. Investigation of a possible submarine landslide at the Var delta front

(Nice slope - SE France), Canadian Geotechnical Journal.

Terzaghi, K., 1956. Varieties of submarine slope failures. Proc., 8th. Texas Conf. Soil Mech.

592 Found. Eng.: 1-41.

593

594

595

596

597

598

599

600

601

602
Xie, M., Esaki, T., Cai, M., 2004. A GIS-based method for locating the critical 3D slip surface in a slope. Computers and Geotechnics, 31, 267-277.

Yu, H. S., Salgado, R., Sloan, S. W., Kim, J. M., 1998. Limit analysis versus limit equilibrium for slope stability, J. Geotech. Geoenviron. Eng., 124(1), 1 -11. 
List of Tables and Figures

608

609

610 Table 1: Comparisons of 2D and 3D-safety factors for the homogeneous slope (adapted from

Xie et al., 2004)

612

Table 2: Mean and standard deviation values for James Bay soil parameters.

614

Table 3: Comparison of slope stability results for James Bay embankment; mean factors of

616 safety, probability of failure and reliability index (SLOPE/W analysis from Krahn and Lam,

Table 4: Su distribution with depth model for the Nice airport slope from CPTU data

(equation 1) for slope stability analysis; mean value and standard deviation .

Figure 1: Bathymetry of the Nice continental slope; the white rectangle corresponds to the slide area located in the vicinity of the Nice airport (adapted from Mas et al., 2007)

Figure 2: Bathymetry in the vicinity of the 1979 Nice slide; the embankment which disappeared during the slide is represented with a dashed line on the post-slide map.

628 Figure 3: Probability density functions (PDF) with different mean and standard deviation parameters (adapted from Christian et al., 1994). The probability to have the failure

630 (probability to have $\mathrm{F}<1.0$ ) is higher with the PDF 2 according to the respective areas. Thus, 631 the factor of safety associated to $5 \%$ probability to have a lower value is lower for the PDF 2 
632 (high mean and high standard deviation) compared to the PDF 1 (low mean and low standard

633 deviation).

634

635 Figure 4: 2D horizontal (a) and 2D vertical (b) projections of the critical failure surface for 636 the homogeneous slope; FOS=1.41 (rectangular shape).

637

638 Figure 5: 2D horizontal (a) and 2D vertical (b) projections of the critical failure surface for 639 the homogeneous slope; FOS=1.35 (free shape).

640

Figure 6: James Bay configuration for average conditions (from Krahn \& Lam,, 2007 ).

642

Figure 7: Shape and position of critical slip surface (from Krahn \& Lam,, 2007).

644

Figure 8: Critical slip surfaces (surface projection and vertical profile) and corresponding

646 safety factors for different geometry; black line correspond to the 2D-critical slip surface

647 defined by El-Ramly et al. (2002) and Krahn \& Lam (2007) for the James Bay embankment.

648

649 Figure 9: Present-day slope gradient in the vicinity of the 1979 Nice slide; a dashed line

650 represents the slide scar (top) and the different escarpments (bottom).

651

652 Figure 10: Tip resistance (qc) and lateral friction (fs) measurements for different sites on the

653 shelf in the viciniy of the Nice airport; the shear zone is suggested by the decrease observed

654 around 25 meter depth on both profiles (qc and fs).

655

656 Figure 11: $3.5 \mathrm{khz}$ profile $\mathrm{CH} 43001$ showing the presence of two discontinuities to the NE at

657 the edge of the slope (for location see figure 3). The two discontinuities prolongation fit quite 
658 well with the small seafloor morphological step. A gas plume or fresh water flow can be

659 observed in the water column above the morphological depression (trace: 3660-3670);

660 from Sultan et al. (submitted).

661

662 Figure 12: Position of CPTU profiles (PRISME cruise, 2007) in the vicinity of the Nice slide escarpment (dashed-line). The arrow represents the direction of the slide.

664

Figure 13: Undrained shear strength profiles versus depth for the 9 sites (modelled using 666 Lunne et al., 1997). The reference data (black line) corresponds to the site PFM11-01.

667

Figure 14: Position of coring (PRISME cruise, 2007) in the vicinity of the 1979 Nice slide escarpment (dashed-line). Filled circles correspond to the unit weight profiles shown on Figure 15.

671

Figure 15: Unit weight profiles versus depth for 6 sites in the vicinity of the Nice airport slide area (from GEOTEK MSCL measurements).

674

Figure 16: Extrapolation of the Su distribution model with depth down to 60 meter depth according to the average gradient; estimation of uncertainty from Su profile modelled with $\mathrm{Nk}=20 ;$ (model 2: 0 to 60 meter depth).

Figure 17: Critical failure surface in terms of probability of failure; weak layer option; 30 meter depth (no vertical exaggeration). meter depth (no vertical exaggeration). 
685 Figure 19: 3D view of the Nice airport bathymetry with slide scar corresponding to the 686 critical failure surface in terms of probability of failure; Su profile from CPTU 12_2 site; 687 weak layer option at 30 meter depth.

688

689 Figure 20: Results of Monte Carlo simulation; probability density function of the safety

690 factor for the critical failure surface down to 30 meter depth; 100 trials.

691

692 Figure 21: 2D horizontal projection of critical failure surface in terms of probability of 693 failure; 60 meter depth.

694

695 Figure 22: Critical failure surface in terms of probability of failure; 60 meter depth.

696

697 Figure 23: 3D critical failure surface with the undrained shear strength profile down to 60 698 meter depth.

699

Figure 24: Results of Monte Carlo simulation; probability density function of the safety

701 factor for the critical failure surface down to 60 meter depth; 100 trials.

702

703

704

705

706

707 


\section{Yamagami and Ueta}

BFGS

1.338

DFP

1.338

Powell

1.338

Simplex

$1.338-1.438$

\section{Greco}

Pattern search

1.327-1.33

Monte Carlo

\section{Malkawi et al.}

Monte Carlo (Random walking)

Xie et al. (2004)

Monte Carlo (3D)

\section{This study}

Energy approach (3D) - deterministic - rectangular shape

Energy approach (3D) - deterministic - free shape

Table 1: Comparisons of 2D and 3D-safety factors for the homogeneous slope (adapted from Xie et al., 2004) 


\begin{tabular}{lcccc}
\multicolumn{1}{c}{ Parameter } & Mean & Standard Deviation & Mean & Standard Deviation \\
Unit weight of sand $(\mathrm{kN} / \mathrm{m} 3)$ & 20.0 & 1.0 & 20.0 & 1.0 \\
Friction angle of sand & 30.0 & 1.0 & 30.0 & 1.0 \\
Thickness of clay crust $(\mathrm{m})$ & 4.0 & 0.48 & 34.5 & - \\
strength of marine clay $(\mathrm{kPa})$ & 34.5 & 8.14 & 31.2 & -14 \\
Vane correction for marine clay & 1.0 & 0.075 & - & 8.65 \\
Strength of lacustrine clay $(\mathrm{kPa})$ & 31.2 & 8.65 & 18.5 & -
\end{tabular}

Table 2: Mean and standard deviation values for James Bay soil parameters. 
800

801

802

803

804

805

806

807

808

809

810

811

812

813

814

816

817

818

819

820

821

822

823

824

825

826

827

828

829

830

831

832

833

834

835

836

837

838

839

840

841

842

843

844

845

846

847

848

849

850

851

852

853

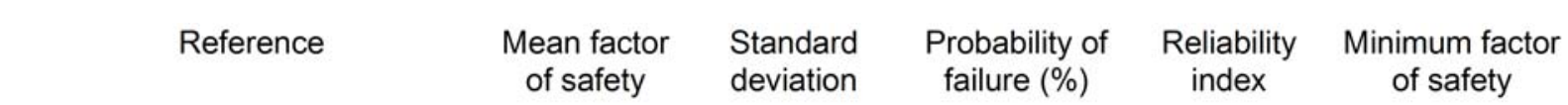

SLOPE/W analysis / 2D-model

1.46

0.210

1.4

2.2

0.725

(Krahn \& Lam, 2007)

1.80

0.038

21.0

Table 3: Comparison of slope stability results for James Bay embankment; mean factors of safety, probability of failure and reliability index (SLOPE/W analysis from Krahn and Lam, 2007) 


\begin{tabular}{cccc}
$\begin{array}{c}\text { Depth } \\
(\mathrm{m})\end{array}$ & $\begin{array}{c}\text { Su mean } \\
(\mathrm{kPa})\end{array}$ & $\begin{array}{c}\text { Uncertainty } \\
(\mathrm{kPa})\end{array}$ & $\begin{array}{c}\text { Standard deviation } \\
(\mathrm{kPa})\end{array}$ \\
\hline $\mathrm{Y}$ & $\times$ & $+/-\left(3^{*} \mathrm{SD}\right)$ & $\mathrm{SD}$ \\
\hline $0-10$ & 13 & 3 & 1 \\
\hline $10-15$ & 18 & 6 & 2 \\
\hline $15-20$ & 23 & 8 & 3 \\
\hline $20-30$ & 29 & 18 & 6 \\
\hline $30-40$ & 40 & 11 & 4 \\
\hline $40-50$ & 49 & 12 & 4 \\
\hline $50-60$ & 58 & 14 & 5 \\
\hline
\end{tabular}

871

Table 4: Undrained shear strength distribution with depth model for the Nice airport slope from CPTU data (equation 1) for slope stability analysis; mean value and standard deviation .

875

876

877 
901

902

903

904

905

906

907

908

909

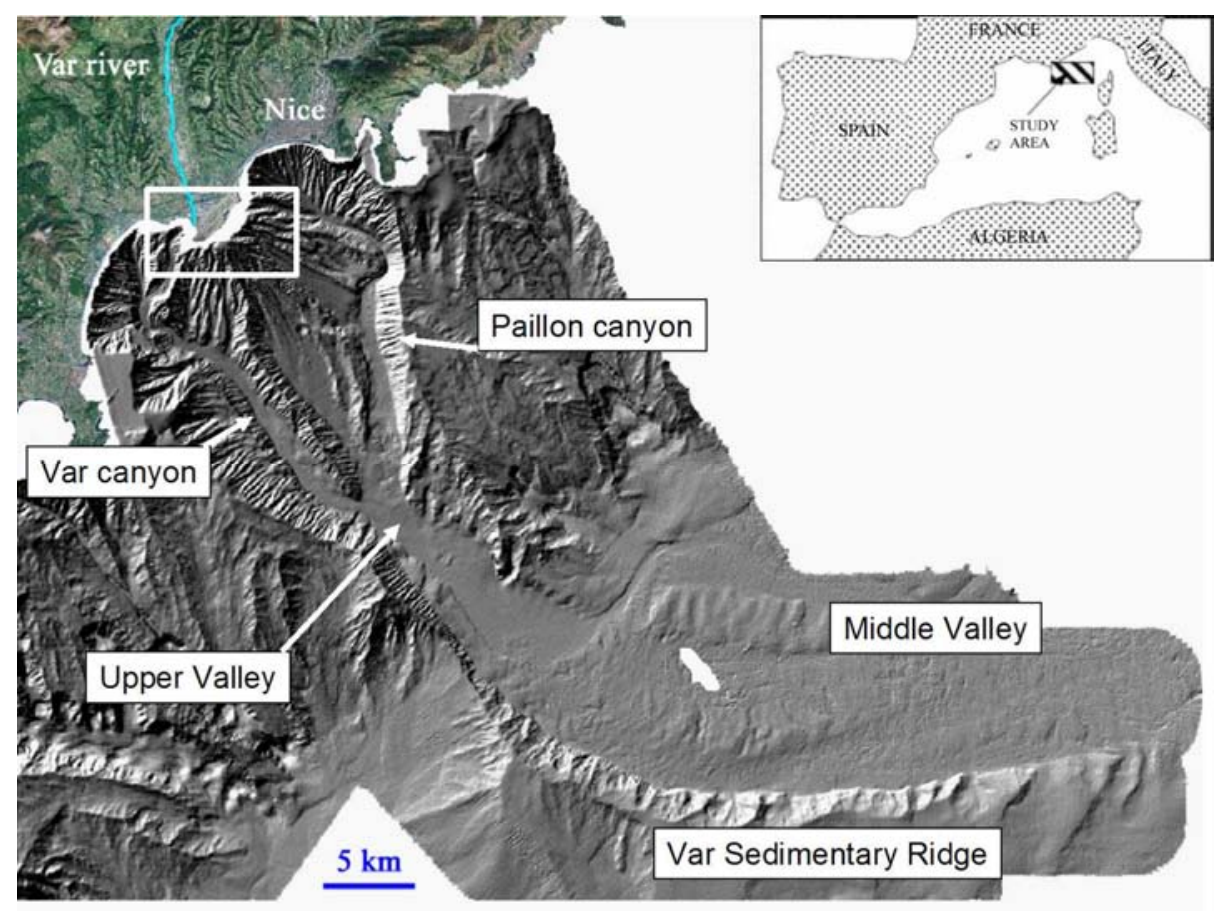

Figure 1: Bathymetry of the Nice continental slope; the white rectangle corresponds to the slide area located in the vicinity of the Nice airport (adapted from Mas et al., 2007) 
Bathymetry in the vicinity of the Nice airport
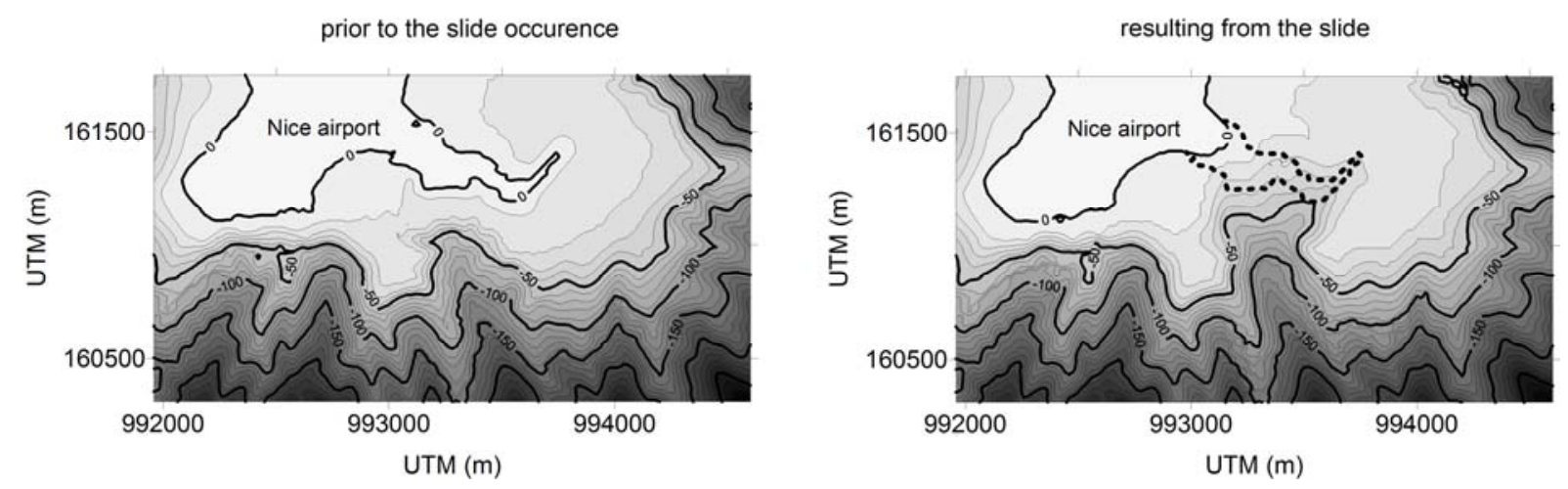

Figure 2: Bathymetry in the vicinity of the 1979 Nice slide; the embankment which disappeared during the slide is represented with a dashed line on the post-slide map. 

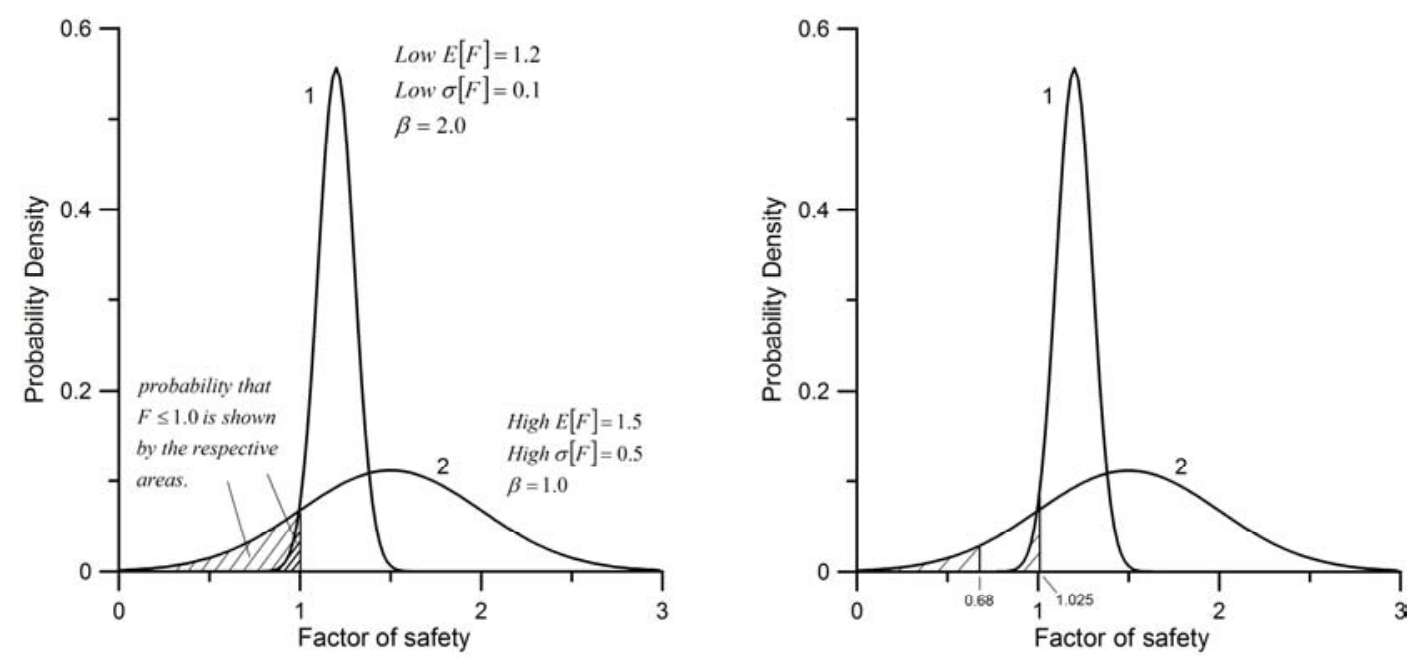

Figure 3: Probability density functions (PDF) with different mean and standard deviation parameters (adapted from Christian et al., 1994). The probability to have the failure (probability to have $\mathrm{F}<1.0$ ) is higher with the PDF 2 according to the respective areas. Thus, the factor of safety associated to $5 \%$ probability to have a lower value is lower for the PDF 2 (high mean and high standard deviation) compared to the PDF 1 (low mean and low standard deviation). 

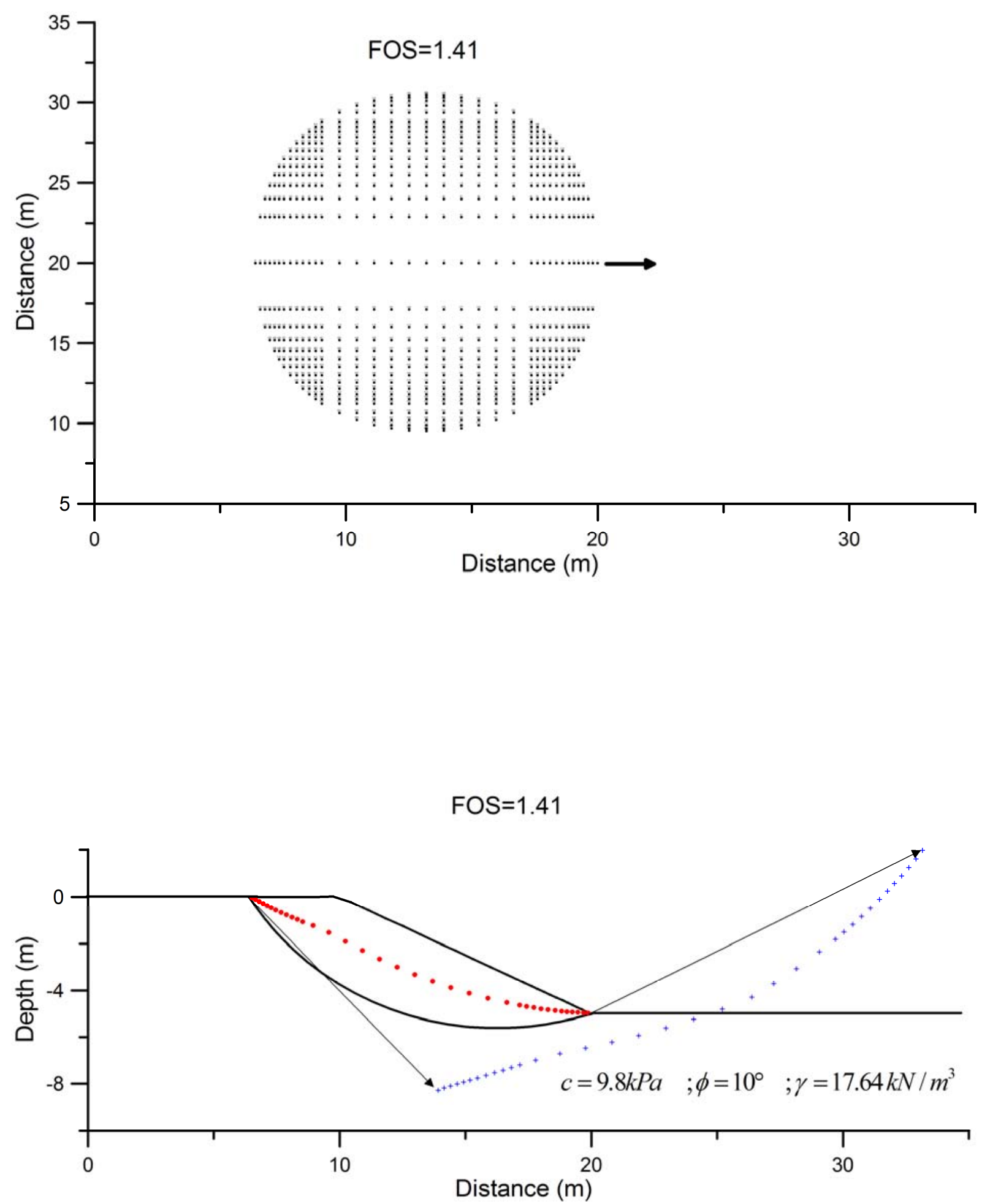

Figure 4: 2D horizontal (a) and 2D vertical (b) projections of the critical failure surface for 1031 the homogeneous slope; $\mathrm{FOS}=1.41$ (rectangular shape). 

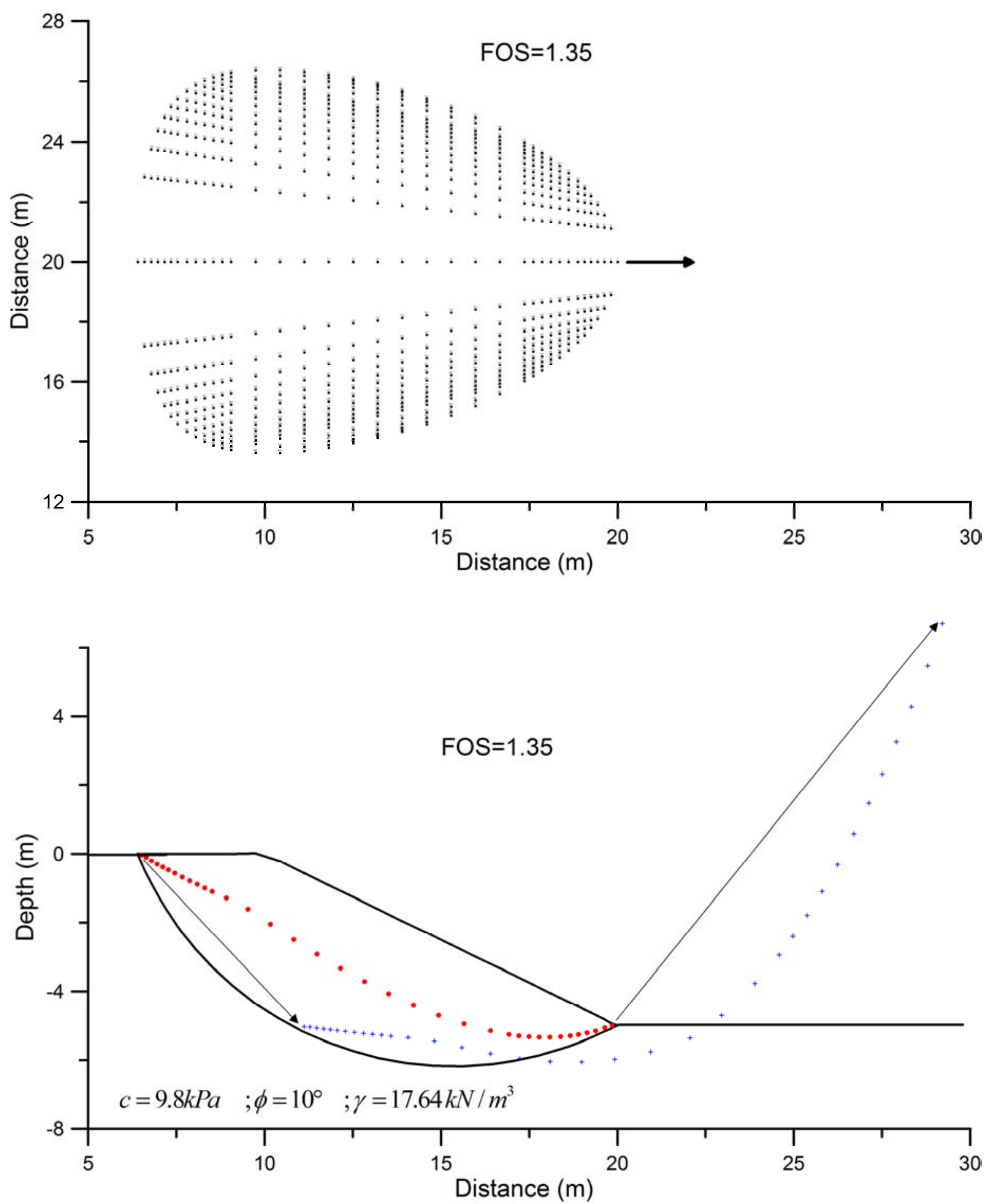

Figure 5: 2D horizontal (a) and 2D vertical (b) projections of the critical failure surface for the homogeneous slope; FOS=1.35 (free shape). 


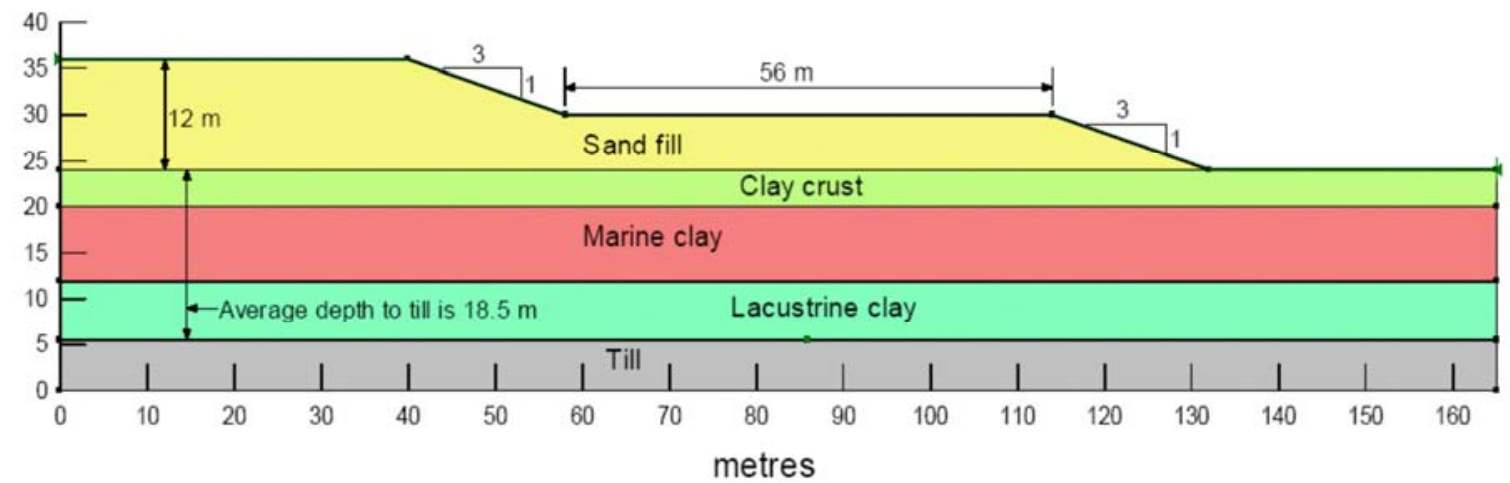

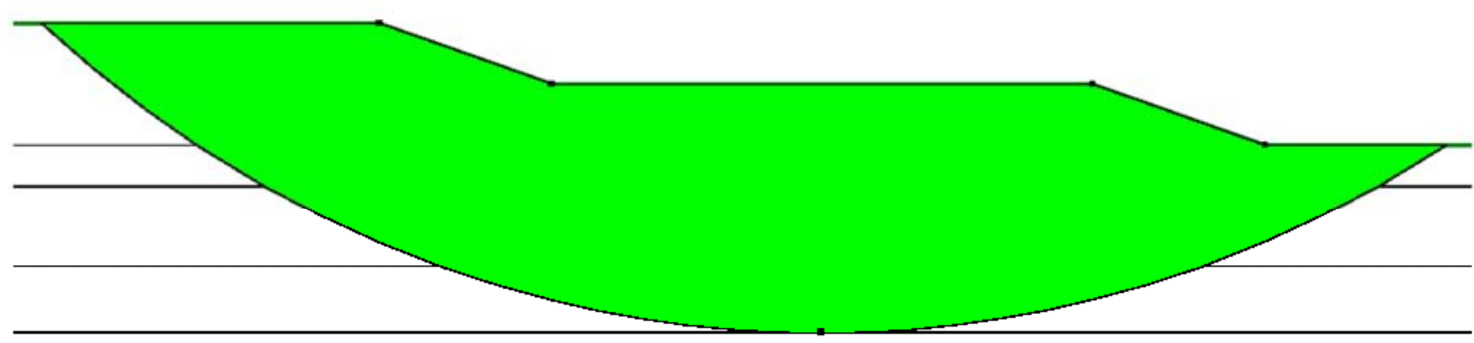

Till

1062

1063

1064

1065

1066

1067

1068

1069

1070

1071

1072

1073

1074

1075

1076

1077

1078

1079

1080

1081

1082

Figure 6: James Bay configuration for average conditions (from Krahn \& Lam,, 2007 ).

Figure 7: Shape and position of critical slip surface (from Krahn \& Lam,, 2007). 

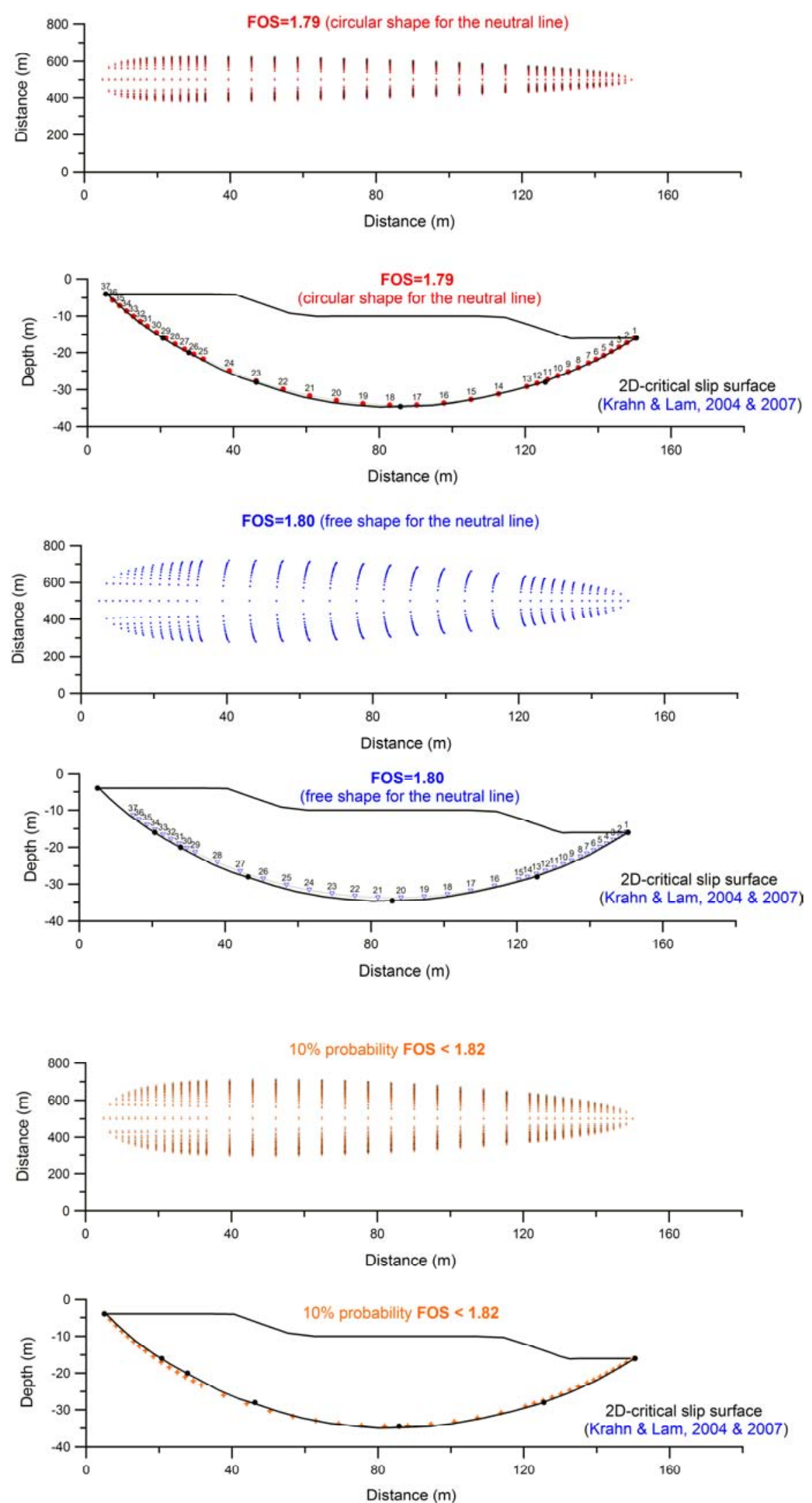

Figure 8: Critical slip surfaces (surface projection and vertical profile) and corresponding safety factors for different geometry; black line correspond to the 2D-critical slip surface defined by El-Ramly et al. (2002) and Krahn \& Lam (2007) for the James Bay embankment. 
1090

1091

1092

1093

1094

1095

1096

1097

1098

1099

1100
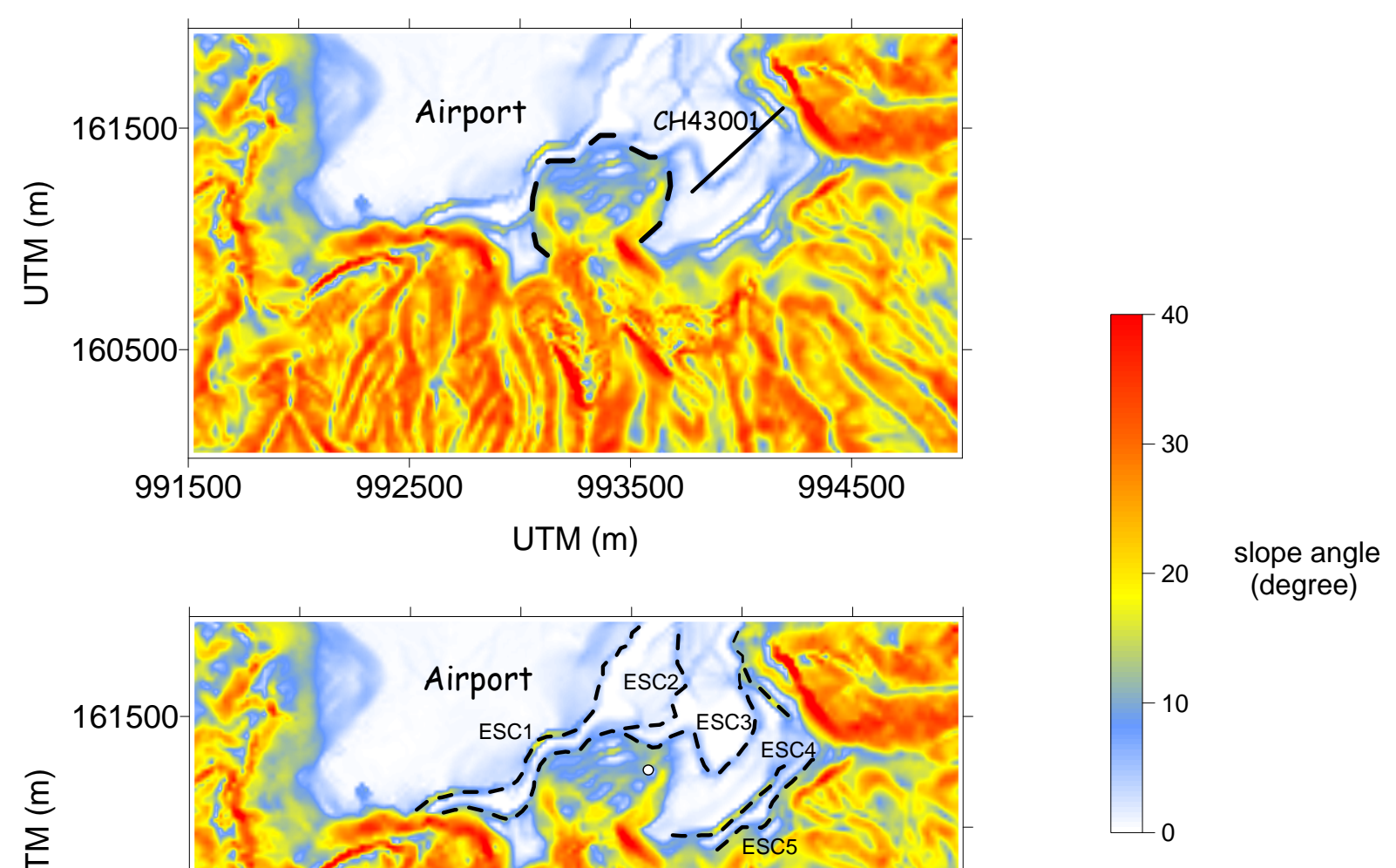

Figure 9: Present-day slope gradient in the vicinity of the 1979 Nice slide; a dashed line represents the slide scar (top) and the different escarpments (bottom). 
$12-02$

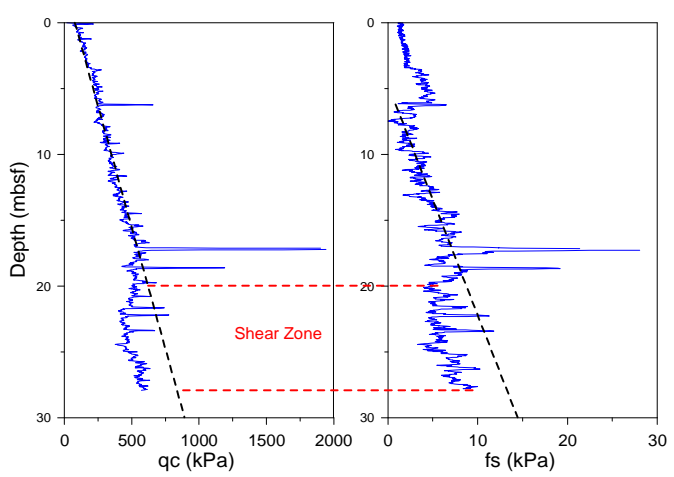

12-03

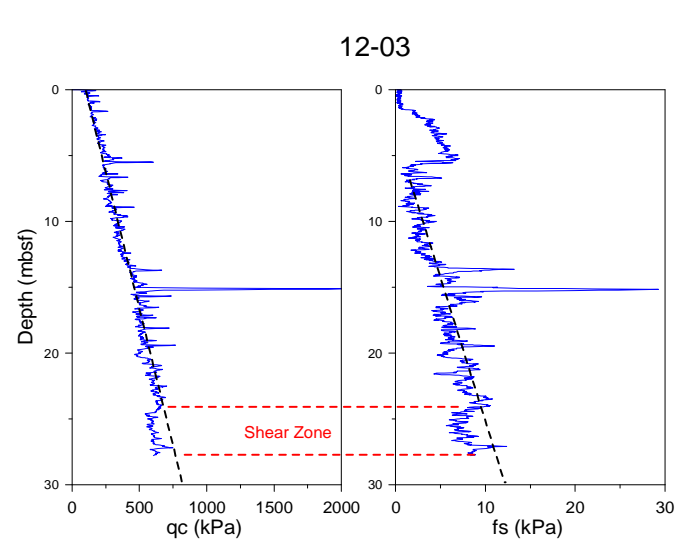

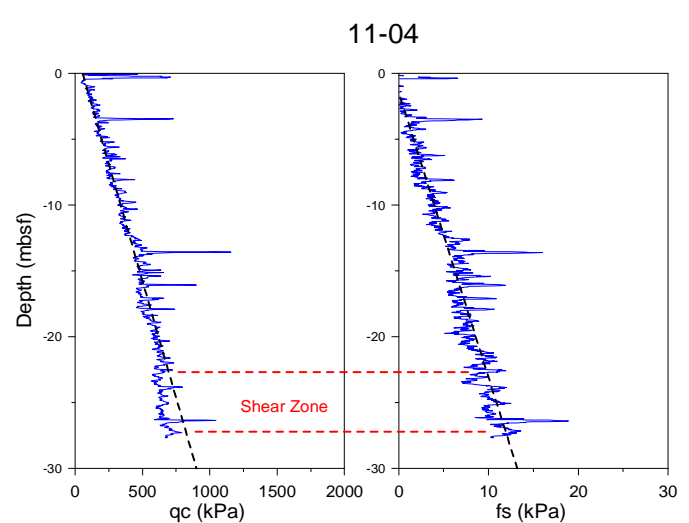

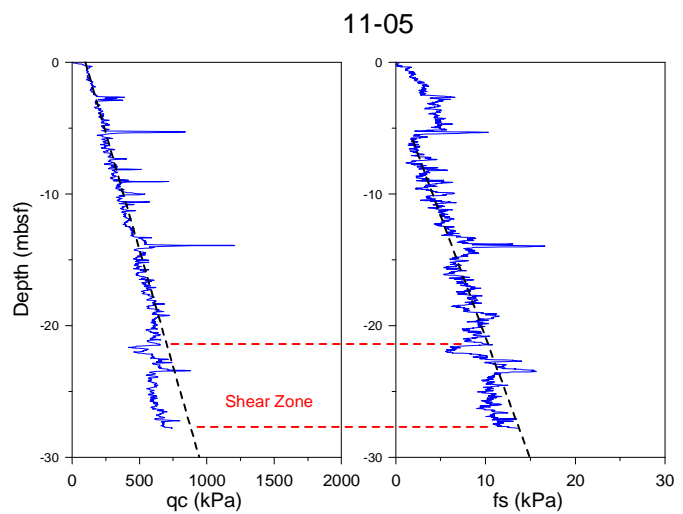

Figure 10: Tip resistance (qc) and lateral friction (fs) measurements for different sites on the

1134 shelf in the viciniy of the Nice airport; the shear zone is suggested by the decrease observed

1135 around 25 meter depth on both profiles (qc and fs); sites location are shown on Figure 12. 


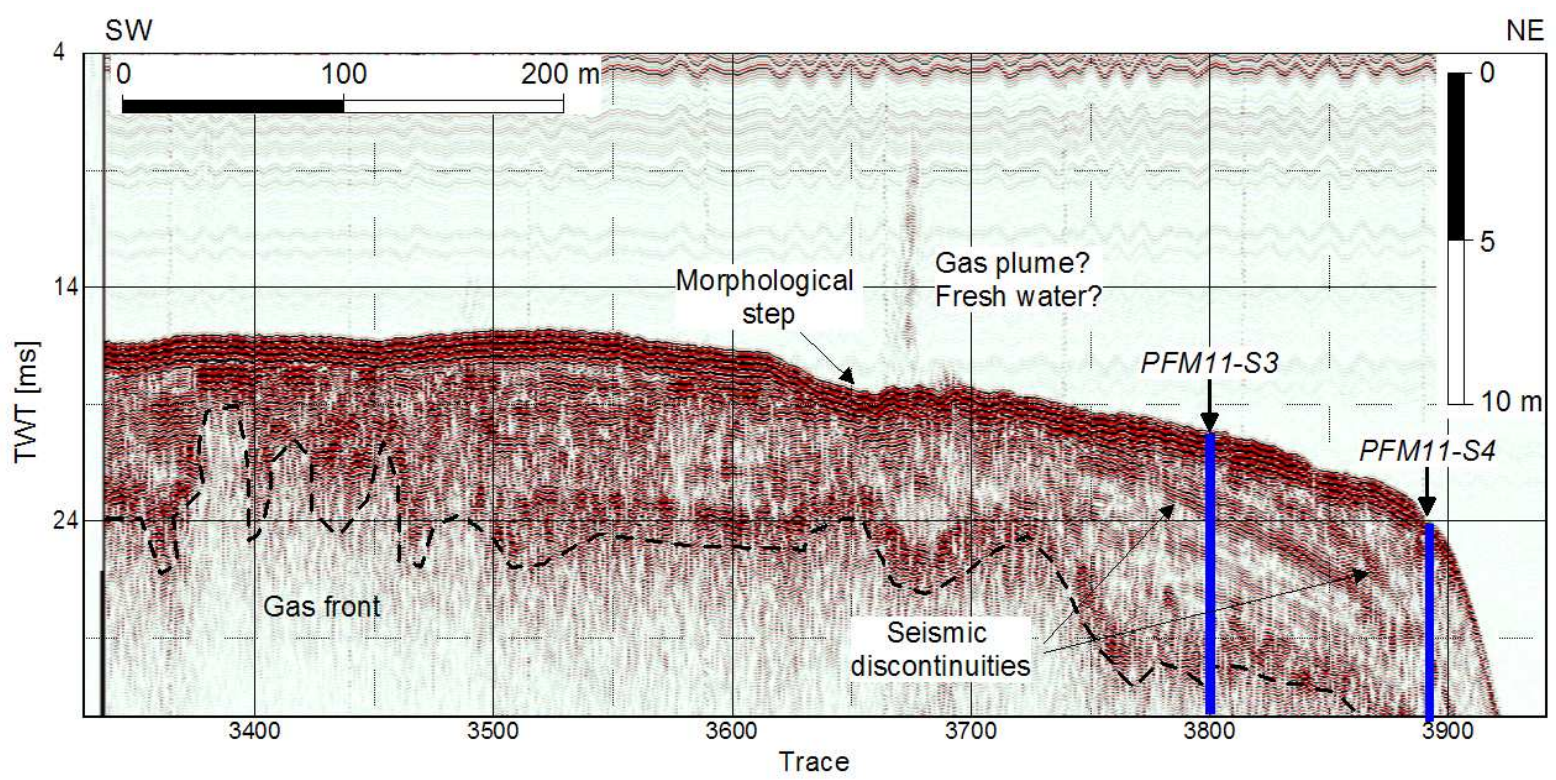

Figure 11: $3.5 \mathrm{khz}$ profile $\mathrm{CH} 43001$ showing the presence of two discontinuities to the $\mathrm{NE}$ at

1163 the edge of the slope (for location see figure 9). The two discontinuities prolongation fit quite

1164 well with the small seafloor morphological step. A gas plume or fresh water flow can be observed in the water column above the morphological depression (trace: 3660-3670); PFM11-S3 and PFM11-S4 corrspond to PFM11-3 and PFM11-4 respectively in this paper; 


\section{CPTU sites (PENFELD) PRISME cruise - Nice airport}

Figure 12: Position of CPTU profiles (PRISME cruise, 2007) in the vicinity of the Nice slide

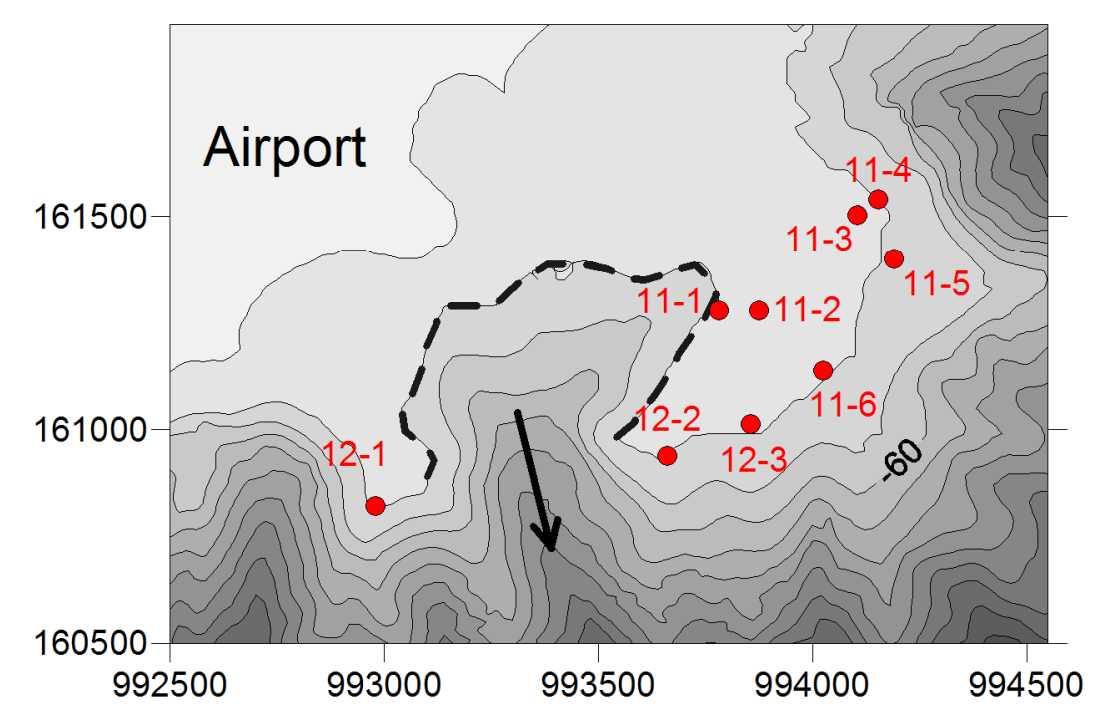
escarpment (dashed-line). The arrow represents the direction of the slide. 

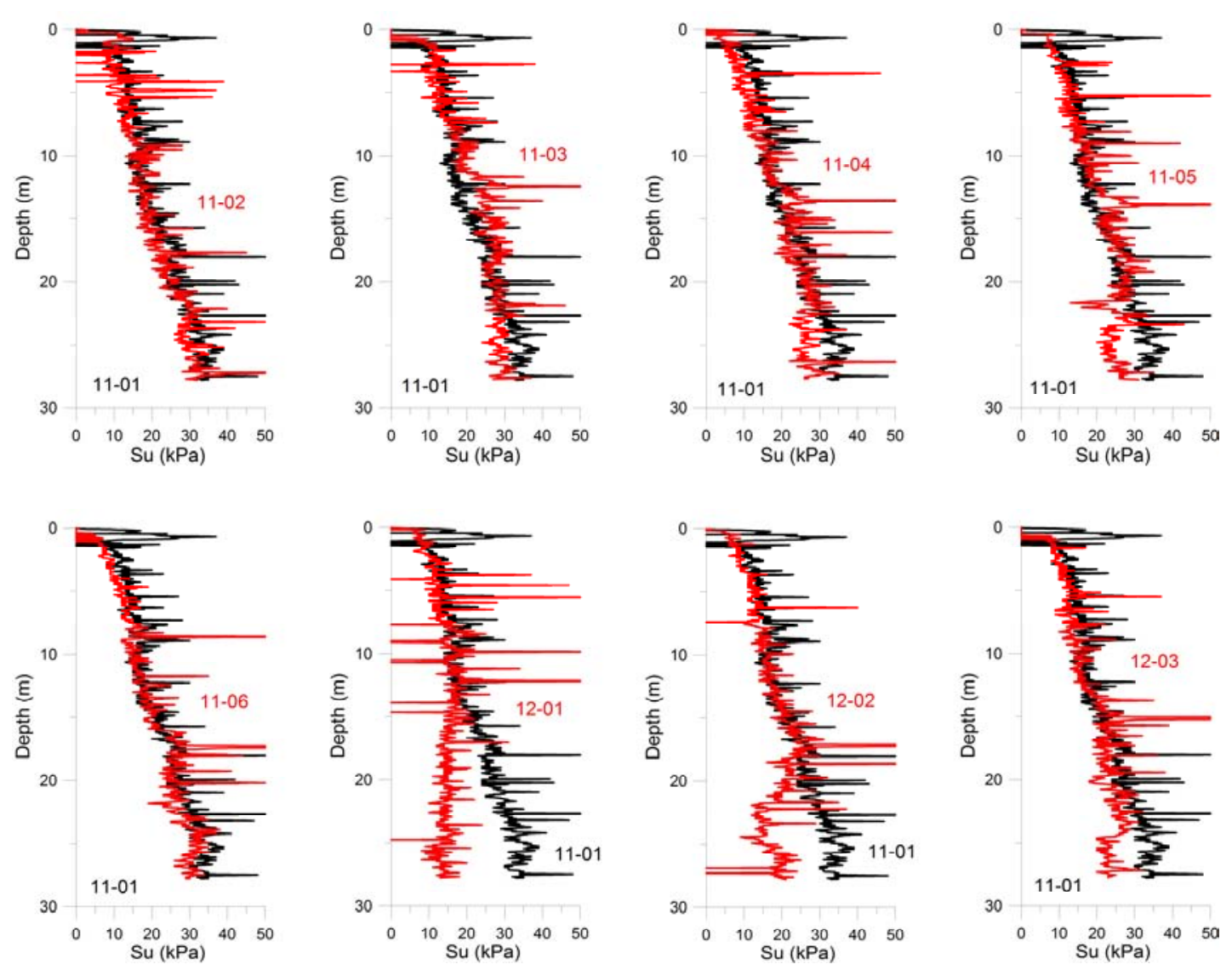

Figure 13: Undrained shear strength profiles versus depth for the 9 sites (modelled using 


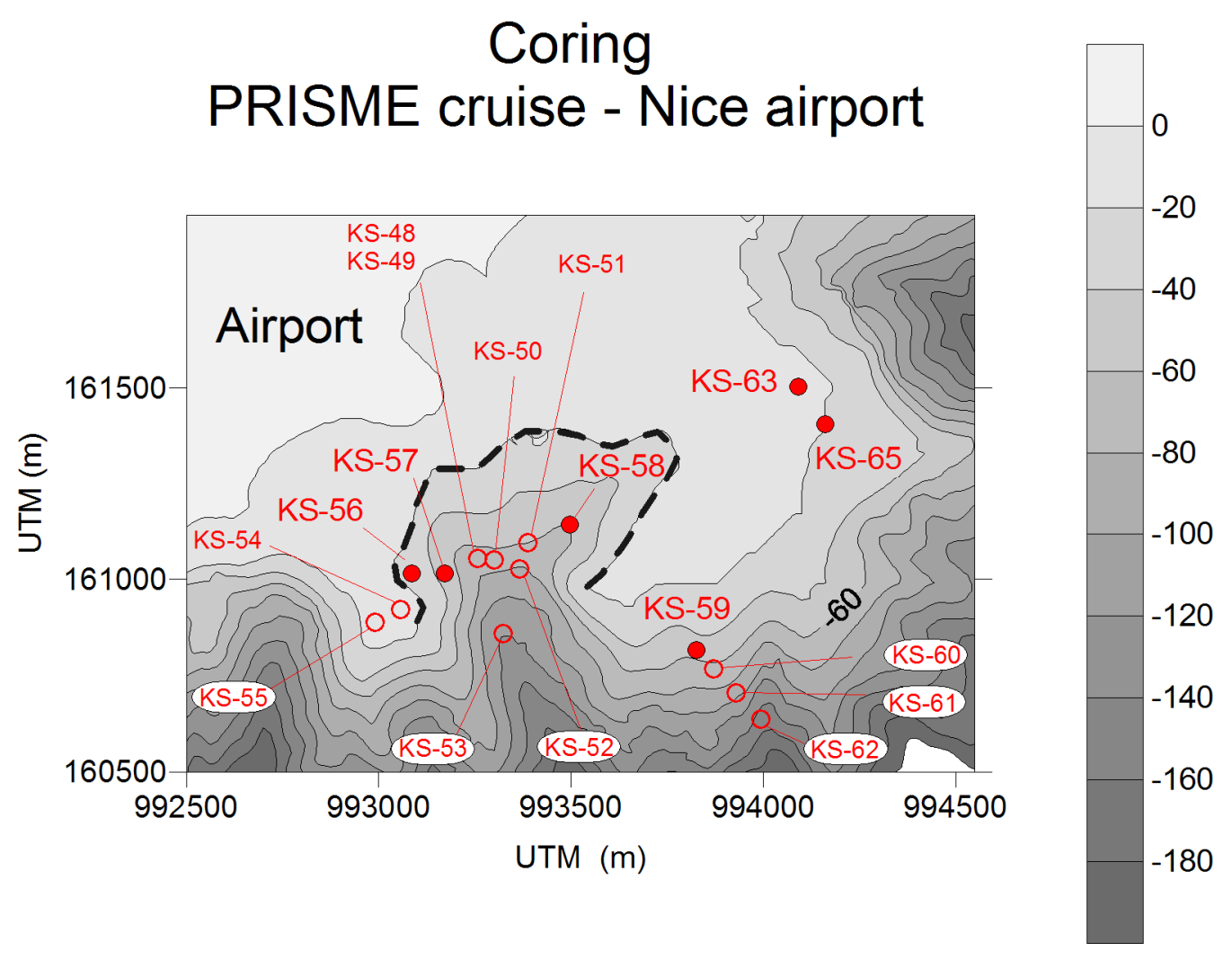

Figure 14: Position of coring (PRISME cruise, 2007) in the vicinity of the 1979 Nice slide escarpment (dashed-line). Filled circles correspond to the unit weight profiles shown on Figure 15. 

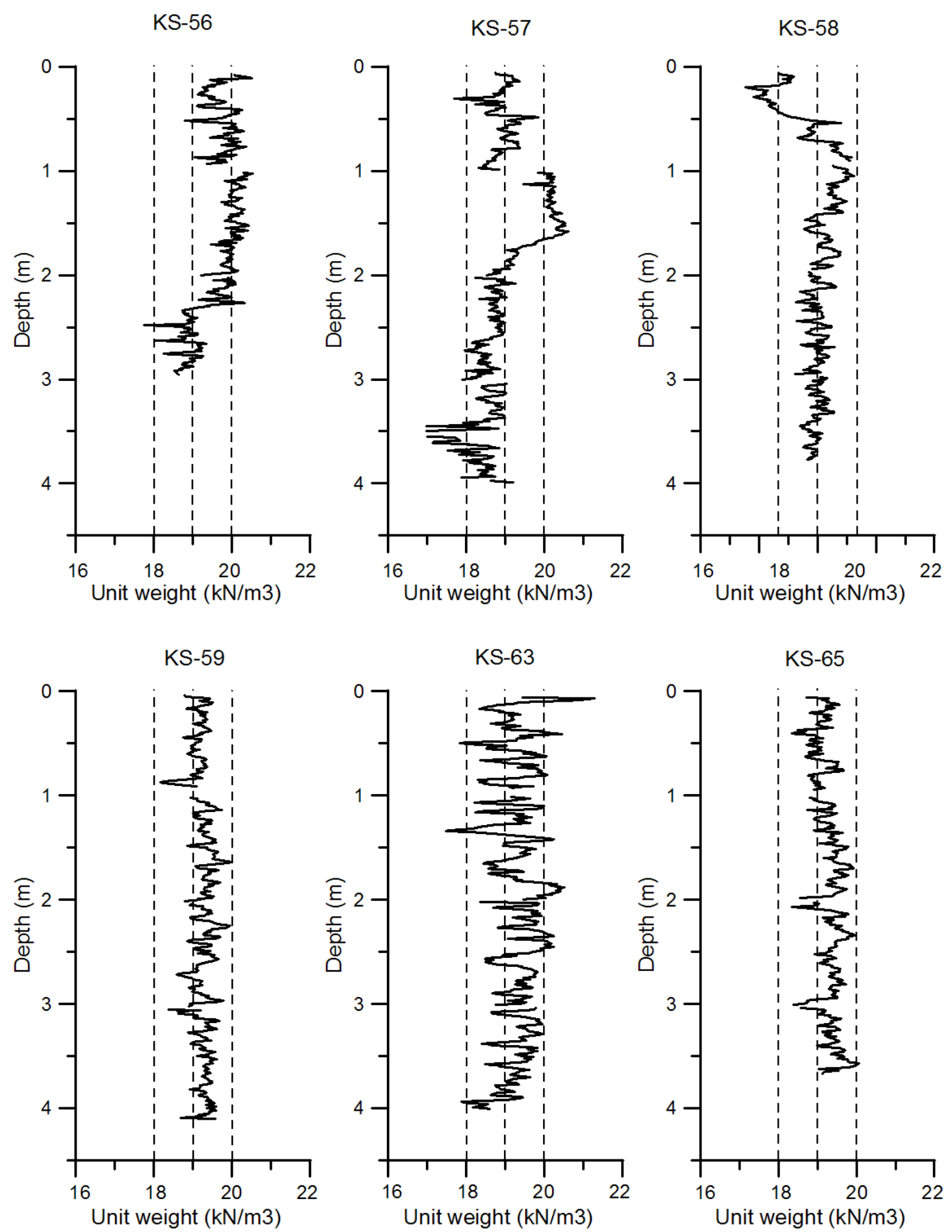

Figure 15: Unit weight profiles versus depth for 6 sites in the vicinity of the Nice airport slide area (from GEOTEK MSCL measurements). 

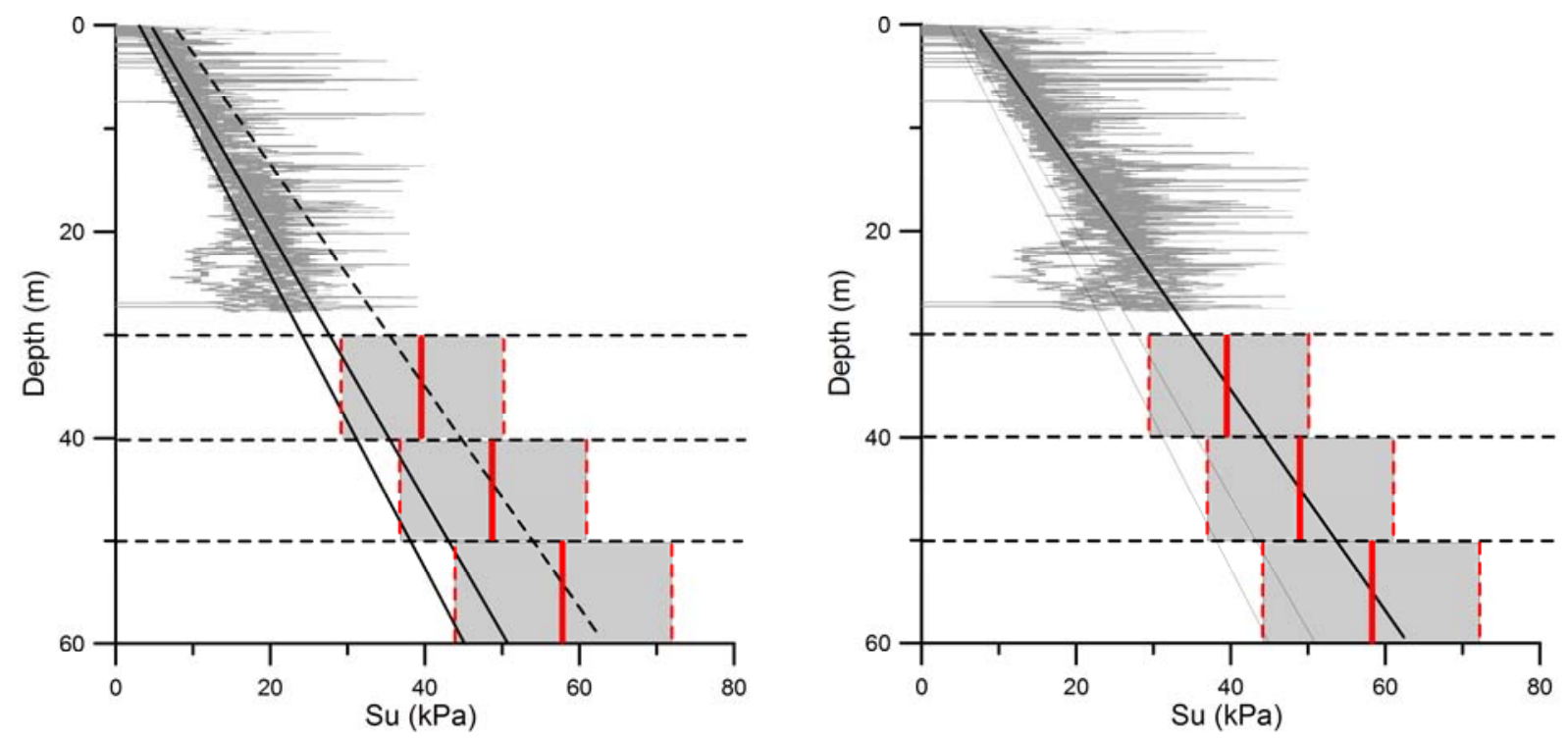

Figure 16: Extrapolation of the Su distribution model with depth down to 60 meter depth according to the average gradient; estimation of uncertainty from Su profile modelled with $\mathrm{Nk}=20$; (model 2: 0 to 60 meter depth). 
1342

1343

1344

1345

1346

1347

1348

1349

1350

1351

1353

1354

1355

1356

1357

1358

1359

1360

1361

1362

1363

1364

1365

1366

1367

1368

1369

1370

1371

1372

1373

1374

1375

1376

\section{Critical probabilistic failure surface}

( $50 \%$ probability of failure)

30 meter depth max - $640000 \mathrm{~m} 3$

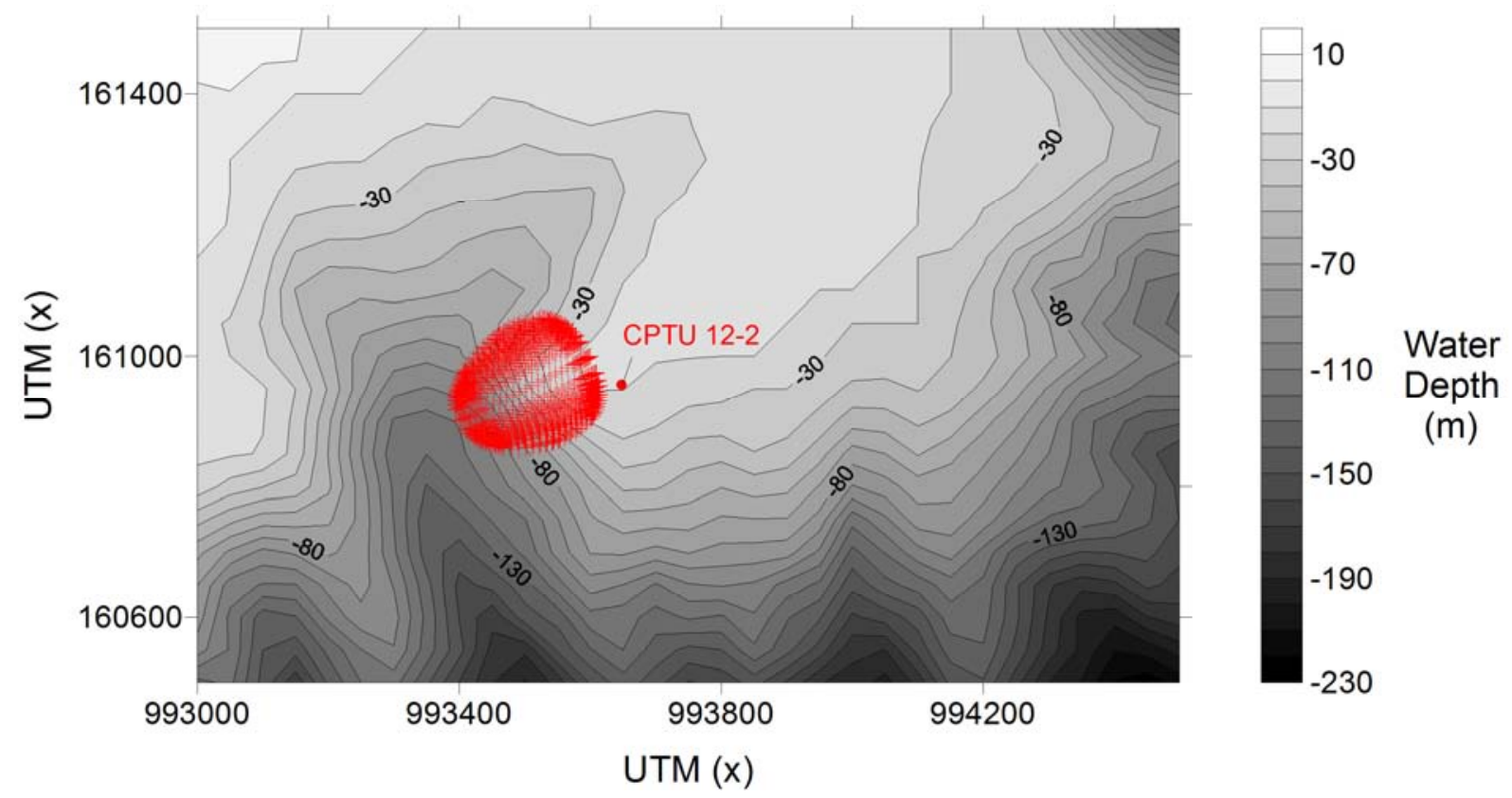

Figure 17: Critical failure surface in terms of probability of failure; weak layer option; 30 meter depth (no vertical exaggeration). 


\section{Nice airport Critical failure surface $-50 \%$ probability of failure}

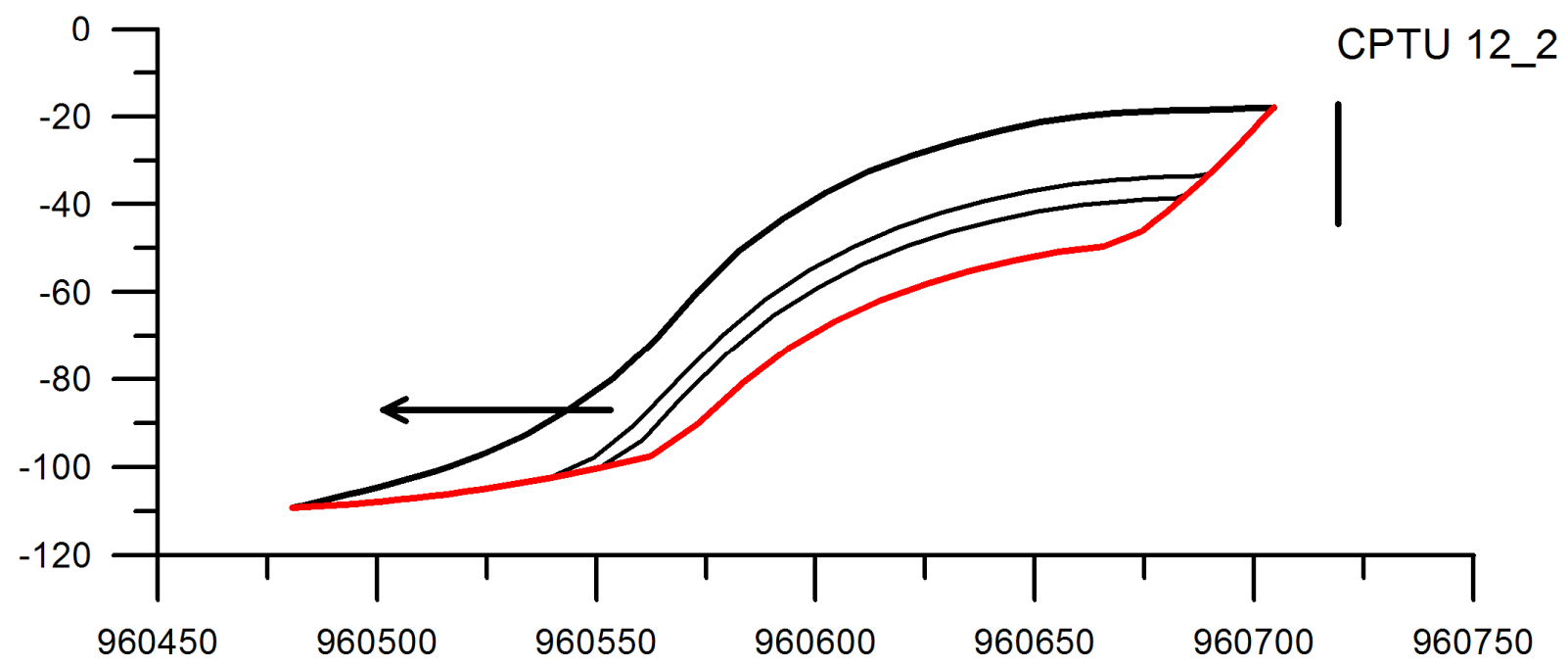

Figure 18: Critical failure surface in terms of probability of failure; 30 meter depth (no vertical exaggeration). The convex shape was imposed during computations (weak layer option). 


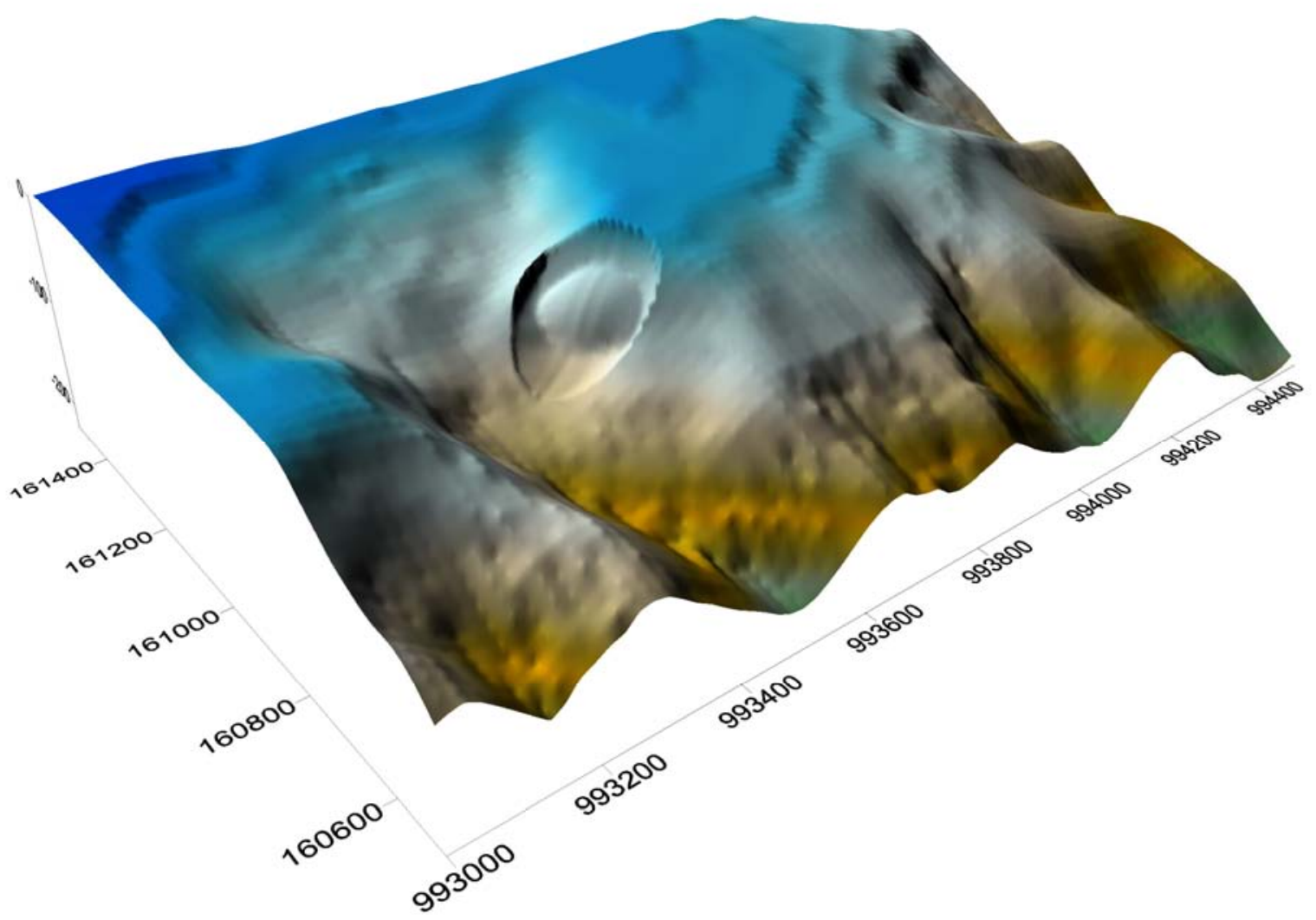

Figure 19: 3D view of the Nice airport bathymetry with slide scar corresponding to the critical failure surface in terms of probability of failure; Su profile from CPTU 12_2 site; weak layer option at 30 meter depth. 


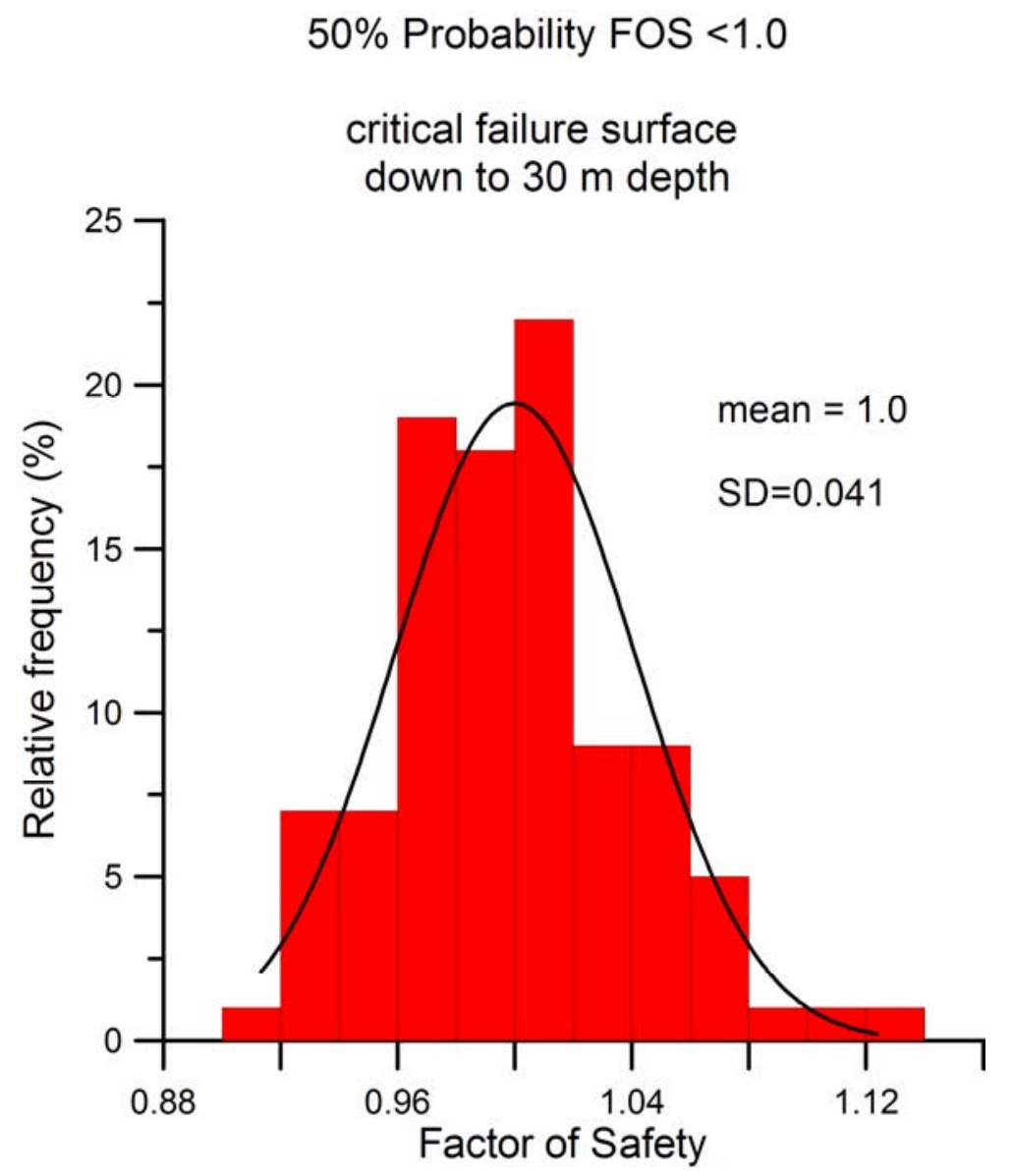
Factor of Safety

Figure 20: Results of Monte Carlo simulation; probability density function of the safety factor for the critical failure surface down to 30 meter depth; 100 trials. 
1479

1480

1481

1482

1483

1484

1485

1486

1487

1488

1489

1490

1491

1492

Critical probabilistic failure surface down to 60 meter depth

$(5 \%$ probability FOS $<1.05)$

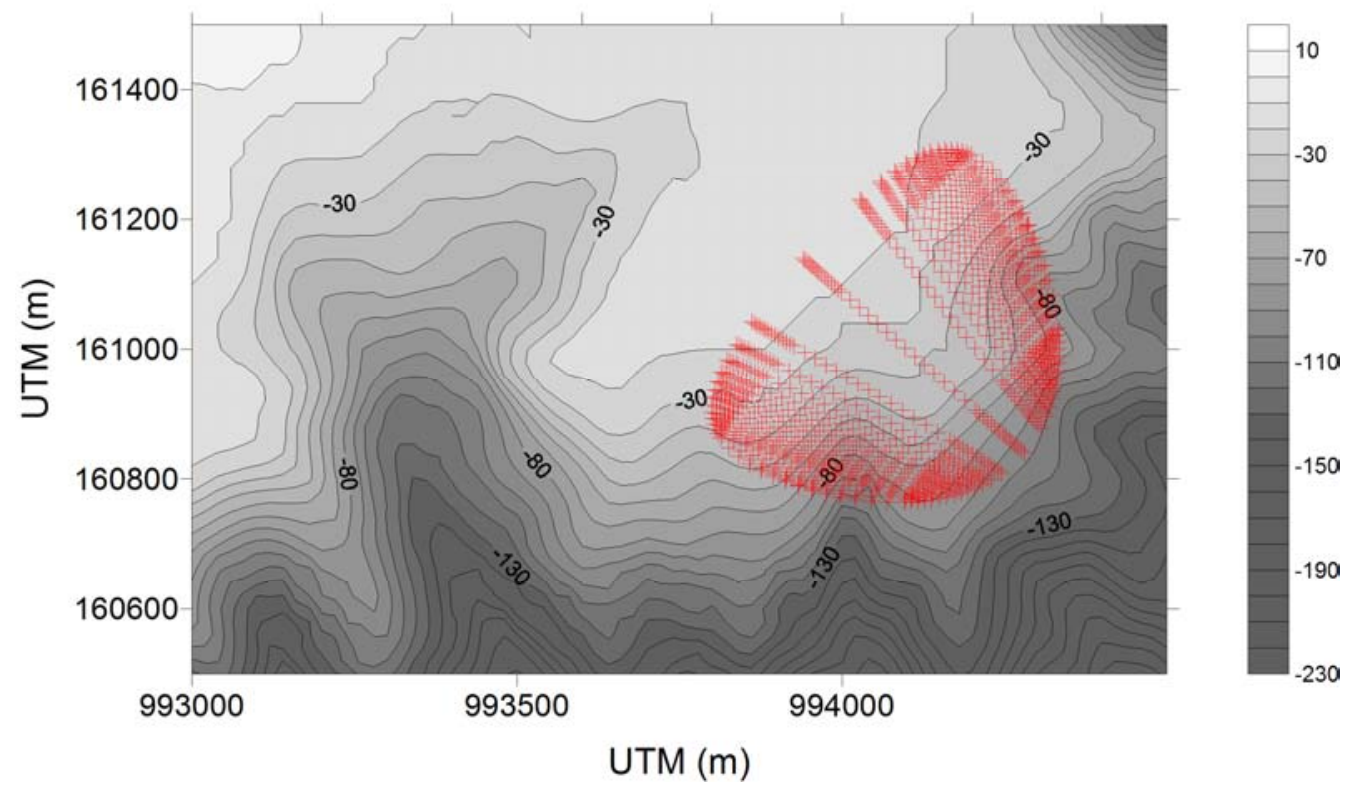

1493

1495

1496

1497

1498

1499

1500

1501

1502

1503

1504

1505

1506

1507

1508

1509

1510

1511

1512

1513

1514

Figure 21: 2D horizontal projection of critical failure surface in terms of probability of failure; 60 meter depth. 
1515

1516

1517

1518

1519

1520

1521

1522

1523

1524

1525

1526

1527

1528

1529

1530

1531

1532

1534

1535

1536

1537

1538

1539

1540

1541

1542

1543

1544

1545

1546

1547

1548

1549

1550

1551

1552

1553

1554

1555

Nice Airport Slope

Critical probabilistic failure surface

down to 60 meter depth

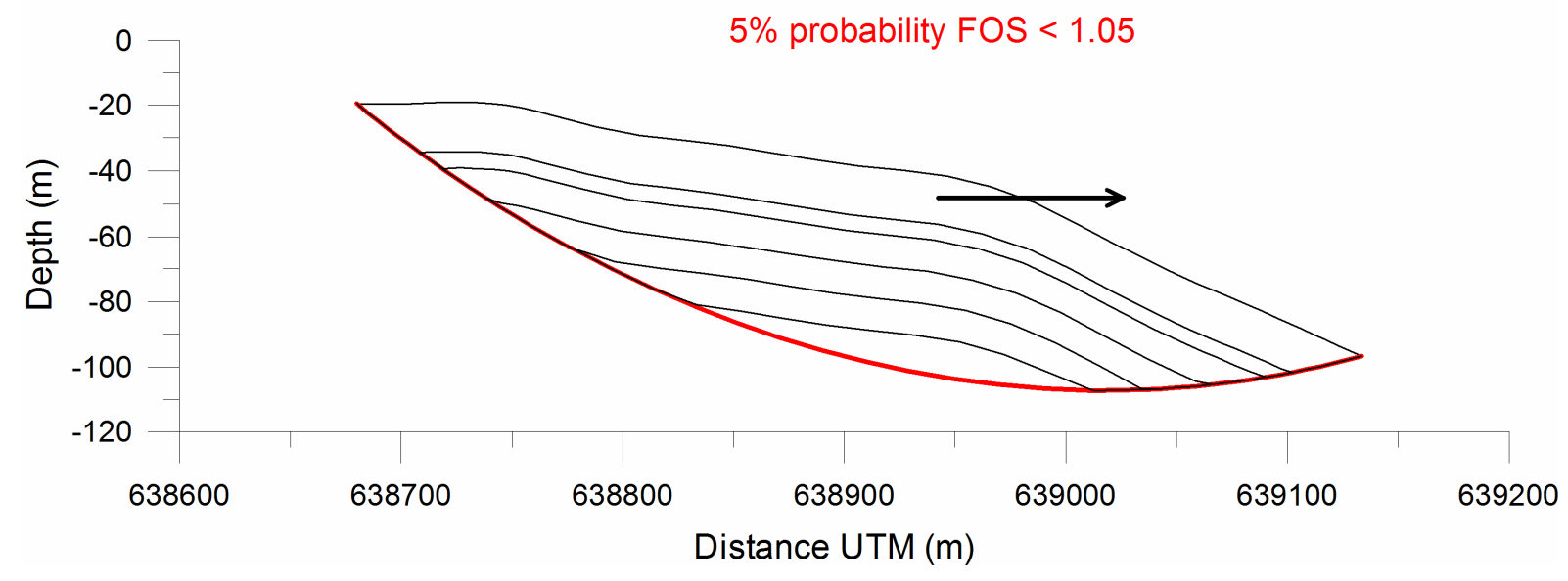

Figure 22: Critical failure surface in terms of probability of failure; 60 meter depth. 
1556

1557

1558

1559

1560

1561

1562

1563

1564

1565

1566

1567

1568

1569

1570

1571

1572

1573

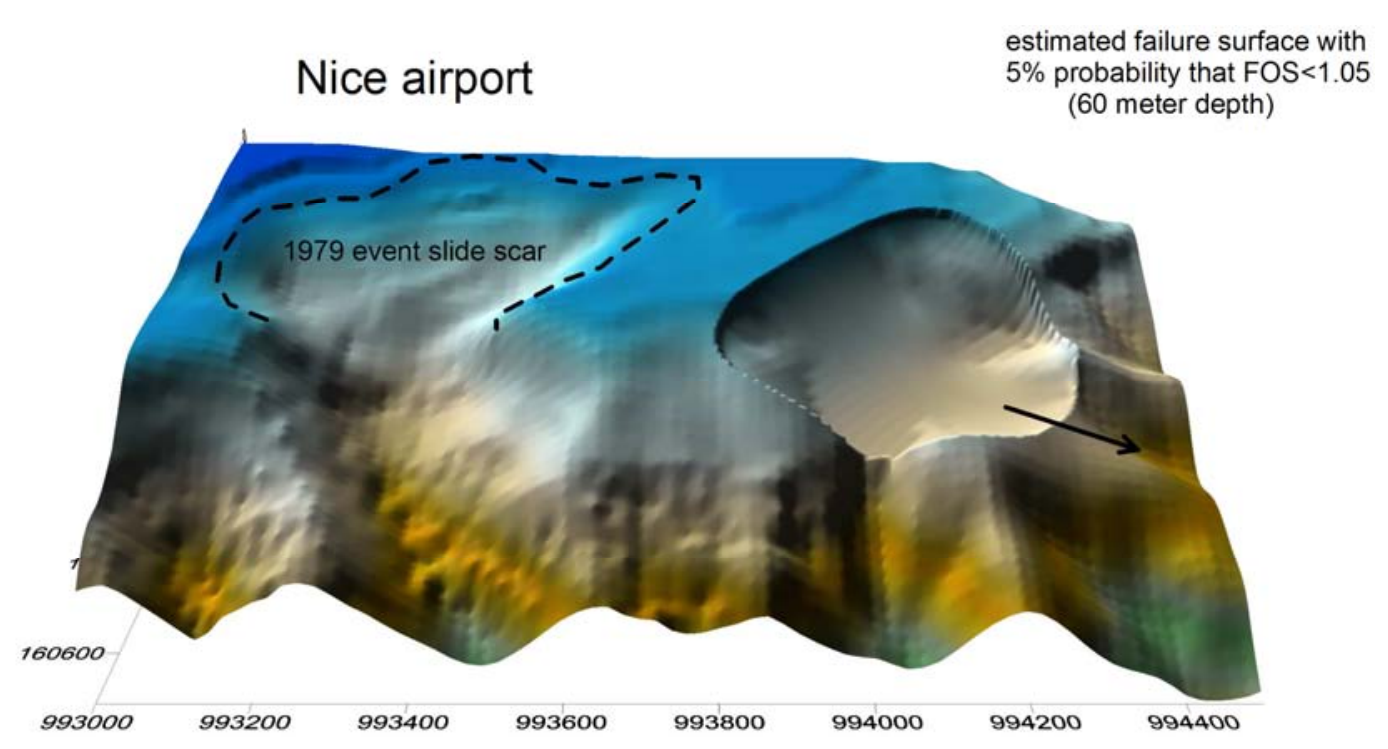

Figure 23: 3D critical failure surface with the undrained shear strength profile down to 60 meter depth. 


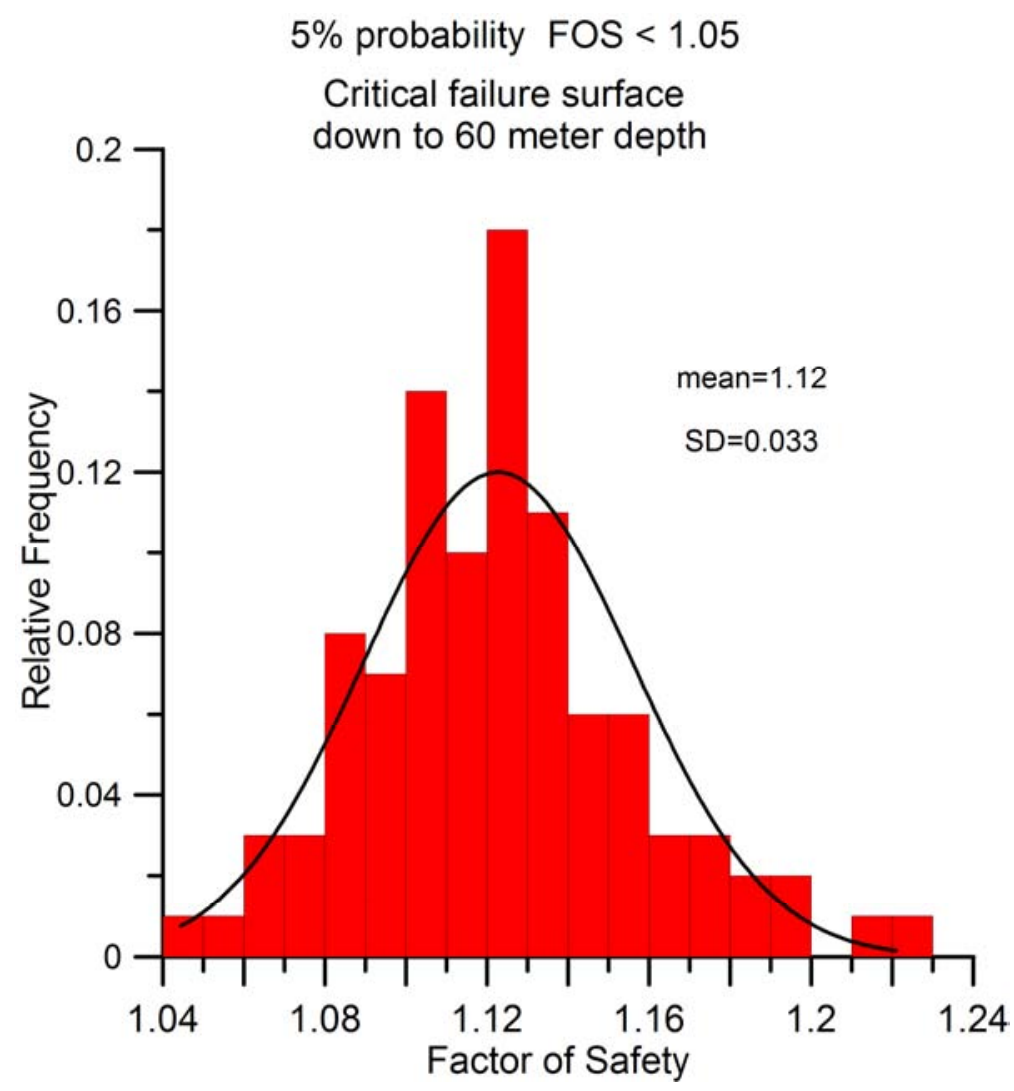

Figure 24: Results of Monte Carlo simulation; probability density function of the safety factor for the critical failure surface down to 60 meter depth; 100 trials. 